\title{
Atrophy but Not Death of Adult Septal Cholinergic Neurons after Ablation of Target Capacity to Produce mRNAs for NGF, BDNF, and NT3
}

\author{
M. V. Sofroniew, ${ }^{1}$ J. D. Cooper, ${ }^{1}$ C. N. Svendsen, ${ }^{1}$ P. Crossman, ${ }^{1}$ N. Y. Ip, ${ }^{2}$ R. M. Lindsay, ${ }^{2}$ F. Zafra, ${ }^{3}$ \\ and $\mathrm{D}$. Lindholm ${ }^{3}$
}

'Department of Anatomy and MRC Cambridge Centre for Brain Repair, University of Cambridge, CB2 3DY Cambridge, United Kingdom, ${ }^{2}$ Regeneron Pharmaceuticals, Tarrytown, New York 10591, and ${ }^{3}$ Department of Neurochemistry, MaxPlanck Institute for Psychiatry, 82152 Martinsried, Germany

\begin{abstract}
The effect of unilateral excitotoxic ablation of hippocampal neurons was investigated on (1) the local production of mRNA for NGF and related neurotrophins, (2) the amount of NGF protein in the septal region, and (3) the viability and appearance of afferent septal cholinergic neurons in adult rats. After near complete ablation of hippocampal neurons, total levels of NGF, brain-derived neurotrophic factor (BDNF), and neurotrophin-3 (NT3) mRNA measured by quantitative Northern blot analysis in the hippocampal remnant fell significantly, to less than $25 \%$ of control values by $28 \mathrm{~d}$ and to less than $9 \%$ by $\mathbf{3 0 0} \mathrm{d}$. In the septal region ipsilateral to such lesions, NGF protein levels measured by ELISA fell significantly, to about $35 \%$ of control values, but the number of immunohistochemically detected cholinergic neurons did not decline significantly for up to $500 \mathrm{~d}$. Instead, the cholinergic neurons persisted in an atrophied state, exhibiting severe shrinkage and reduced staining for the transmitter-synthesizing enzyme ChAT. The parameters of cell size and ChAT staining intensity correlated significantly with the amount of hippocampal tissue present. These findings indicate that in adult rats, target-derived NGF, BDNF, and NT3 do not regulate the survival of septal cholinergic neurons in proportion to the number of target neurons present. Moreover, the findings suggest that one or more of these targetderived neurotrophins regulate the structural and chemical phenotype of these neurons in the adult.
\end{abstract}

[Key words: NGF, brain-derived growth factor, neurotrophin-3, basal forebrain cholinergic neurons]

During critical periods of development in the PNS, limiting amounts of neurotrophic factors produced in target tissues are thought to regulate the survival and collateral arborization of afferent neurons (Levi Montalcini and Angeletti, 1968; Thoenen and Barde, 1980). NGF, the first neurotrophic factor isolated and structurally characterized, belongs to a family of neurotrophins, including brain-derived neurotrophic factor (BDNF) and

\footnotetext{
Received Jan. 22, 1993; revised Apr. 26, 1993; accepted June 15, 1993.

We thank S. J. Stevens and K. J. Baker for technical assistance, J. Bashford for photography, and Dr. S. B. Dunnett for assistance with the statistics. This work was supported by grants from the MRC, Wellcome Trust, and Merck, Sharp and Dohme Research Laboratories.

Correspondence should be addressed to Michael V. Sofroniew, Department of Anatomy, Downing Street, Cambridge CB2 3DY, England.

Copyright (C) 1993 Society for Neuroscience $0270-6474 / 93 / 135263-14 \$ 05.00 / 0$
}

neurotrophin-3 (NT3), which exhibit a high degree of sequence homology and may have functional interactions (Leibrock et al., 1989; Alderson et al., 1990; Hohn et al., 1990; Maisonpierre et al., 1990; Knüsel et al., 1991). Members of this family are also produced in the CNS, leading to the extrapolation of the neurotrophic hypothesis to the CNS (Korsching, 1986; Barde, 1989).

Neurotrophins continue to be produced throughout adult life in both the PNS and CNS, but their functions in the adult are not well understood and may vary in different neuronal systems. Both sympathetic neurons and sensory neurons have an absolute requirement for NGF for survival during development (Johnson et al., 1980; Thoenen and Barde, 1980). Mature sympathetic neurons appear to remain dependent for survival on a continuous supply of NGF throughout life, but sensory neurons do not (Greene, 1977a,b; Johnson et al., 1986; Eichler and Rich, 1989). Neurotrophic factors that are no longer required for survival may have other functions regarding mature neurons. In addition to its effects on neuronal survival, NGF is able to regulate both collateral branching and transmitter phenotype of various types of neurons in vilro and in vivo (Campenot, 1977; Gnahn et al., 1983; Mobley et al., 1985; Johnson et al., 1986).

Within the CNS, one of the main neural systems in which NGF appears to be active is that of the basal forebrain cholinergic neurons, which provide widespread and topographically organized projections to the hippocampus and cerebral neocortex (Cuello and Sofroniew, 1984; Korsching, 1986). These neurons transport radioactively labeled NGF from their target cortex or hippocampus where NGF and its mRNA are produced, and express low-affinity (p75 NGFR) and high-affinity (p140 $10^{\text {trkA }}$ ) NGF receptors (Seiler and Schwab, 1984; Taniuchi et al., 1986; Ayer-LeLievre et al., 1988; Dawbarn et al., 1988; Holtzman et al., 1992). NGF will also prevent the degeneration of septal cholinergic neurons after axotomy (Hefti, 1986; Williams et al., 1986; Kromer, 1987), but it is not known if this axotomyinduced cell loss is actually due to NGF withdrawal or some other aspect of cellular injury (Sofroniew et al., 1990). NGF and other growth factors such as BDNF, ciliary neurotrophic factor (CNTF), and fibroblast growth factor (FGF) have been shown to protect neurons from cell death in response to physical or chemical injury where the cause of cell death is clearly not due to the withdrawal of the growth factor (Sendtner et al., 1990; Cheng and Mattson, 1991; Hyman et al., 1991).

In this study we investigated whether septal cholinergic neu- 
rons that project to the hippocampus are dependent for survival or maintenance of phenotype on NGF, BDNF, or NT3 derived from target neurons in adult rats. The main cellular source of these neurotrophins in the uninjured adult hippocampus is thought to be neuronal (Ayer-LeLievre et al., 1986; Phillips et al., 1990; Wetmore et al., 1990). To ablate neurons without directly injuring the afferent fibers of the medial septal cholinergic neurons, the excitotoxic amino acid NMDA was stereotaxically injected unilaterally into multiple sites throughout the hippocampus and related regions in young adult rats (Sofroniew et al., 1990). The effects of these lesions were examined on (1) hippocampal levels of mRNA for NGF, BDNF, and NT3, (2) NGF protein levels in the medial septal nucleus in order to estimate the amount of NGF that might be present within septal cholinergic neurons, and (3) the appearance and morphometric parameters of afferent septal cholinergic neurons.

\section{Materials and Methods}

Animals and surgical procedures. Eighty-one young adult (3-6 months) Wistar or Sprague-Dawley rats of either sex, weighing 150-250 gm at the time of surgery, were used in this study. Under ketamine and xylazine anesthesia, animals were given 9 or 15 stereotaxically (Paxinos and Watson, 1986) placed injections of either NMDA solution or vehicle into the brain. All rats received nine injections distributed throughout the hippocampal formation unilaterally. Some rats received an additional six injections into the region of the entorhinal cortex and subiculum. Each injection site received $1 \mu \mathrm{l}$ of either $12 \mu \mathrm{g} / \mu \mathrm{l}$ NMDA(Sigma) or $0.9 \% \mathrm{NaCl}$ (vehicle) delivered over $5 \mathrm{~min}$ via a stainless-steel 29 gauge cannula connected by Teflon tubing filled with paraffin oil to a 1 $\mu l$ syringe driven by a Harvard microinfusion pump. The cannula was left in place for a further 2 min after completion of each injection. An additional group of previously untreated animals underwent complete unilateral transection of the fimbria-fornix (FF) by suction under direct visualization using a Zeiss operating microscope. After survival times ranging from 7 to $500 \mathrm{~d}$, animals were taken either for determination of mRNA levels and ELISA assay in unfixed tissue, or were perfusion fixed for histological evaluation.

$m R N A$ determinations. Under ether anesthesia, rats were decapitated and the brains removed. Using sterile conditions, the hippocampal formation (or remnant), the entorhinal cortex, and the cingulate cortex were dissected bilaterally under an operating microscope. The appearance and wet weight were recorded for each sample and lesions were labeled as complete or partial. RNA was extracted using the guanidium thiocyanate method (Chomczynski and Sacchi, 1987) and a shortened cRNA standard was added before extraction to assess recovery (Lindholm et al., 1987). RNA was glyoxylated, run through a $1.3 \%$ agarose gel, and blotted onto Hybond $\mathrm{N}$ filters. The filters from different groups of rats were consecutively hybridized in two different laboratories with ${ }^{32} \mathrm{P}$-labeled cRNA probes specific for mouse BDNF, mouse NGF, and $\beta$-actin using a $50 \%$ formamide solution (Zafra et al., 1990), or for NGF, BDNF, NT3, and GAPDH (Maisonpierre et al., 1990). The probes were produced by runoff transcription using the P-Gemini system. Autoradiography was conducted at $-70^{\circ} \mathrm{C}$ for various periods of time depending on the intensity of the signals. For quantitative analysis, gels were scanned with a densitometer (Lindholm et al., 1987) and NGF or BDNF mRNA values were corrected for recovery against an added standard consisting of a synthetic shorter fragment of NGF or BDNF mRNA. Values were then normalized relative to a constitutive mRNA level (either $\beta$-actin or GAPDH mRNA) in each sample to correct for potential nonspecific changes in mRNA levels that might have resulted from the experimental procedures (both $\beta$-actin and GAPDH mRNA were used because groups of samples were processed in two different laboratories; Maisonpierre et al., 1990; Zafra et al., 1990). Normalized values were expressed relative to the wet weight of the tissue samplc to obtain a relative value of the total neurotrophin mRNA level per hippocampus or other brain region analyzed (e.g., entorhinal or cingulate cortex). No difference was noted in the values of the left and right sides in control animals (ANOVA) in all regions tested. The mean value of controls was set as $100 \%$ and all other values were expressed as a percentage of the mean control value. The significance of differences between experimental groups was tested by ANOVA with post hoc Newman-Keuls pairwise analysis.

$N G F$ protein determinations. NGF concentrations were determined bilaterally in the medial septal nucleus by two-site ELISA (Spranger et al., 1990). Unfixed tissue was collected for ELISA measurements as described above for the mRNA samples. To dissect the septal region, an approximately 2 -mm-thick frontal section was taken immediately rostral to the decussation of the anterior commissure. A diamond-shaped block was cut from this section as indicated by the dashed lines in Figure $5 \mathrm{~A}$, extending from the corpus callosum in the midline to the tips of the lateral ventricles on either side and back to the midline at the bottom of the section. The diamond-shaped block was bisected along the midline into left and right halves. Using this dissection procedure, much of the lateral septum was excluded from the sample, but the resulting tissue blocks unavoidably contained not only cholinergic neurons of the medial septal nucleus, but also cholinergic neurons in the vertical (VDB) and part of the horizontal (HDB) limbs of the diagonal band. NGF protein determinations were conducted separately on the left or right medial septum using the mouse monoclonal antibody $27 / 21$, and the values obtained were corrected for recovery of added mouse $2.5 \mathrm{~S} \mathrm{NGF}$.

Fixation and processing of tissue for histology. Under terminal barbiturate anesthesia and continuous positive pressure ventilation, rats were fixed by transcardiac perfusion with a vascular rinse followed by a buffered (pH 7.4) solution of $4 \%$ paraformaldehyde, $0.1 \%$ glutaraldehyde (Sofroniew et al., 1987, 1990). Perfused brains were removed, fixed a further $2-3 \mathrm{hr}$ in buffered $4 \%$ paraformaldehyde only, and placed in buffer at $4^{\circ} \mathrm{C}$. Blocks of tissue containing the septal region were sectioned on a vibratome at $40 \mu \mathrm{m}$. Tissue blocks containing the hippocampus and related structures were incubated overnight in $30 \%$ sucrose solution and sectioned on a freezing microtome at $80 \mu \mathrm{m}$. Sections were collected in buffer and stored at $4^{\circ} \mathrm{C}$ until staining.

Immunohistochemical and other staining procedures. Cholinergic neurons were identified by immunohistochemical detection of two markers, choline acetyltransferase (ChAT), the cholinergic synthesizing enzyme, and $\mathrm{p} 75^{\mathrm{NGFR}}$, a low-affinity component of the NGF receptor complex. Alternate vibratome sections through the septal region of perfusion fixed brains were immunohistochemically stained free-floating for either ChAT or low-affinity NGF receptor (p75 NGFR) using wellcharacterized primary monoclonal antibodies and either the peroxidaseantiperoxidase procedure, or the biotin-avidin-peroxidase procedure, with diaminobenzidine as a chromogen (Sofroniew et al., 1990). No difference in the quality of staining was noted between these two procedures. The primary antibodies used were a monoclonal anti-ChAT antibody (Eckenstein and Theonen, 1982) kindly provided by F. Eckenstein (Oregon Health Sciences University), and monoclonal antibody MC-192 (Chandler et al., 1984) kindly provided by E. M. Johnson (Washington Univ., St. Louis). Antibody MC-192 recognizes a lowaffinity NGF receptor $\mathrm{p} 75^{\mathrm{NGFR}}$. A 1:6 series of frozen sections through the hippocampal region of each animal was stained immunohistochemically for glial fibrillary acidic protein (GFAP) using a polyclonal antiserum (DACO) and the procedures described above. All immunohistochemically stained sections were mounted, dried, exposed briefly to dilute osmium tetroxide, and coverslipped from xylene. A further 1:6 series of frozen sections through the hippocampal region of each animal was stained for histochemical detection of AChE (Hedreen et al.,1984), and a 1:3 series of sections was stained with cresyl violet as a Nissl stain.

Morphometric and statistical analysis. The cross-sectional surface areaa of viable neuronal tissue in the hippocampal formation and entorhinal cortex were determined by interactive image analysis using digitized images (captured via a black and white video camera attached to a Zeiss microscope using a with a $1 \times$ objective) and Seescan image analyzer (Cambridge, England). Four standardized levels were measured through each structure for every animal and values were expressed as the total area measured on the left divided by the total area measured on the right side $100 \times$ (i.e., $L / R \times 100$ ) for each animal.

Cell counts, cell size, and optical density measurements of septal cholinergic neurons were made either by interactive image analysis using digitized images (captured via a black and white video camera attached to a Zeiss microscope using a $10 \times$ Planapo objective) and a Seescan image analyzer (Cambridge, England), or using a drawing tube. Septal neurons immunohistochemically stained for either ChAT or p $75^{\mathrm{NGFR}}$ were included in the analysis that had a cross-sectional area of greater than $26 \mu \mathrm{m}^{2}$, a feret diameter greater than $7 \mu \mathrm{m}$, and a roundness factor $\left(K A / P^{2}\right.$, where $K=1.257, A=$ cross-sectional area, and $P=$ perimeter) greater than 0.35 (to eliminate large elongated fibers). Because bilateral 

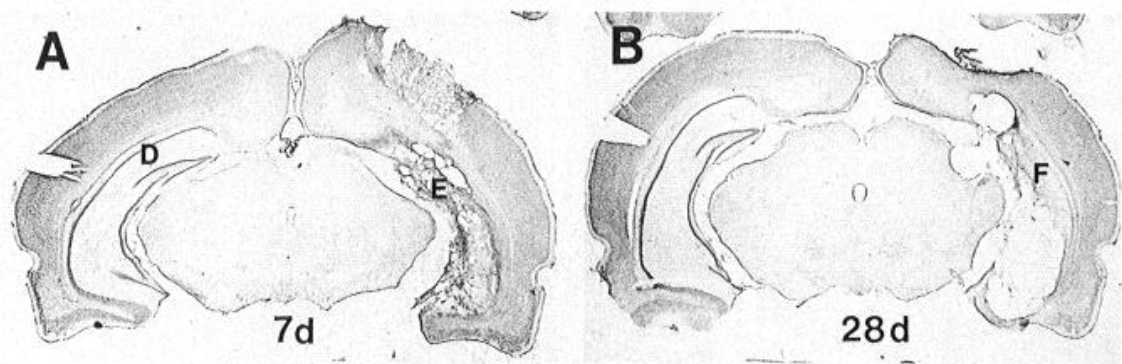

$28 d$
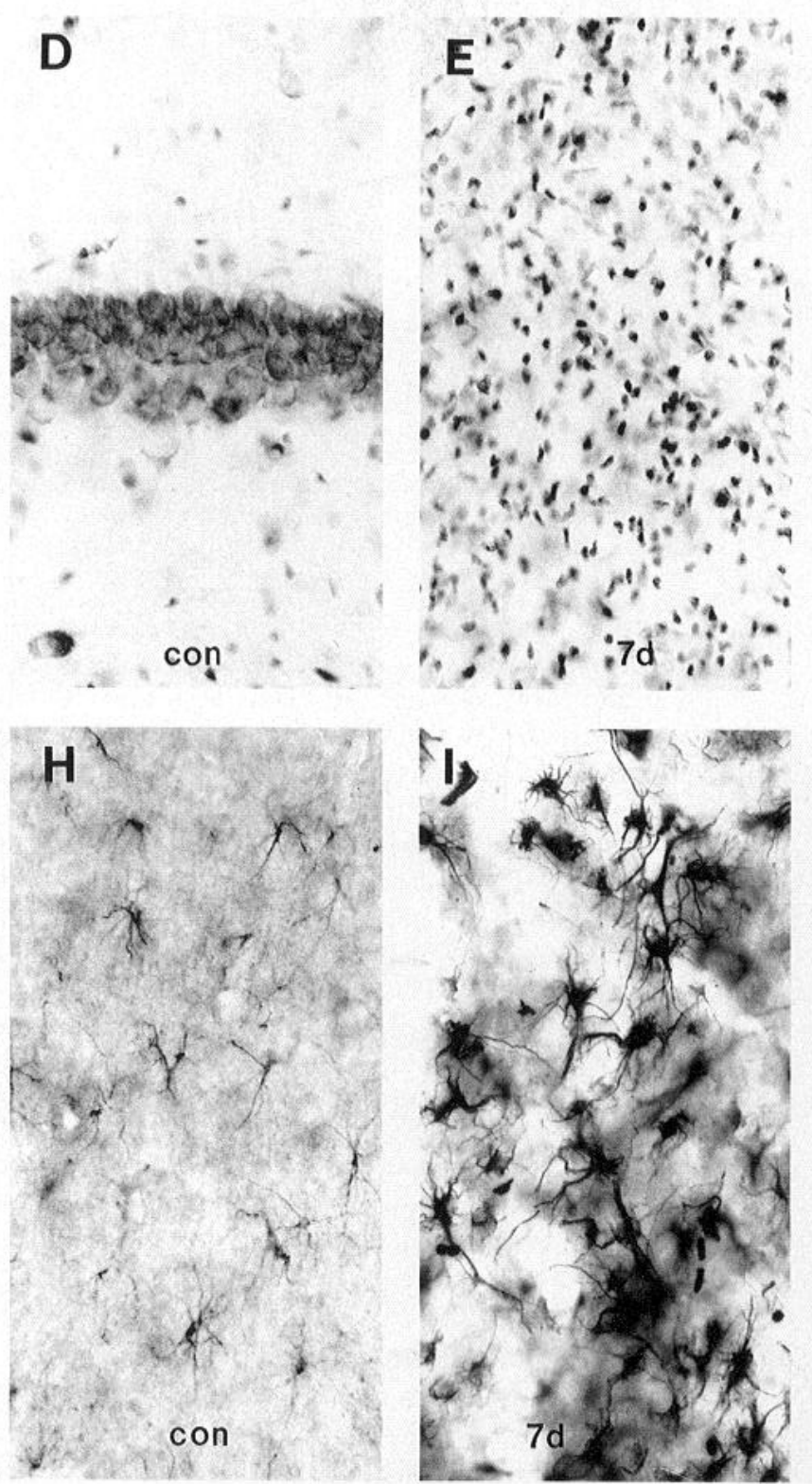
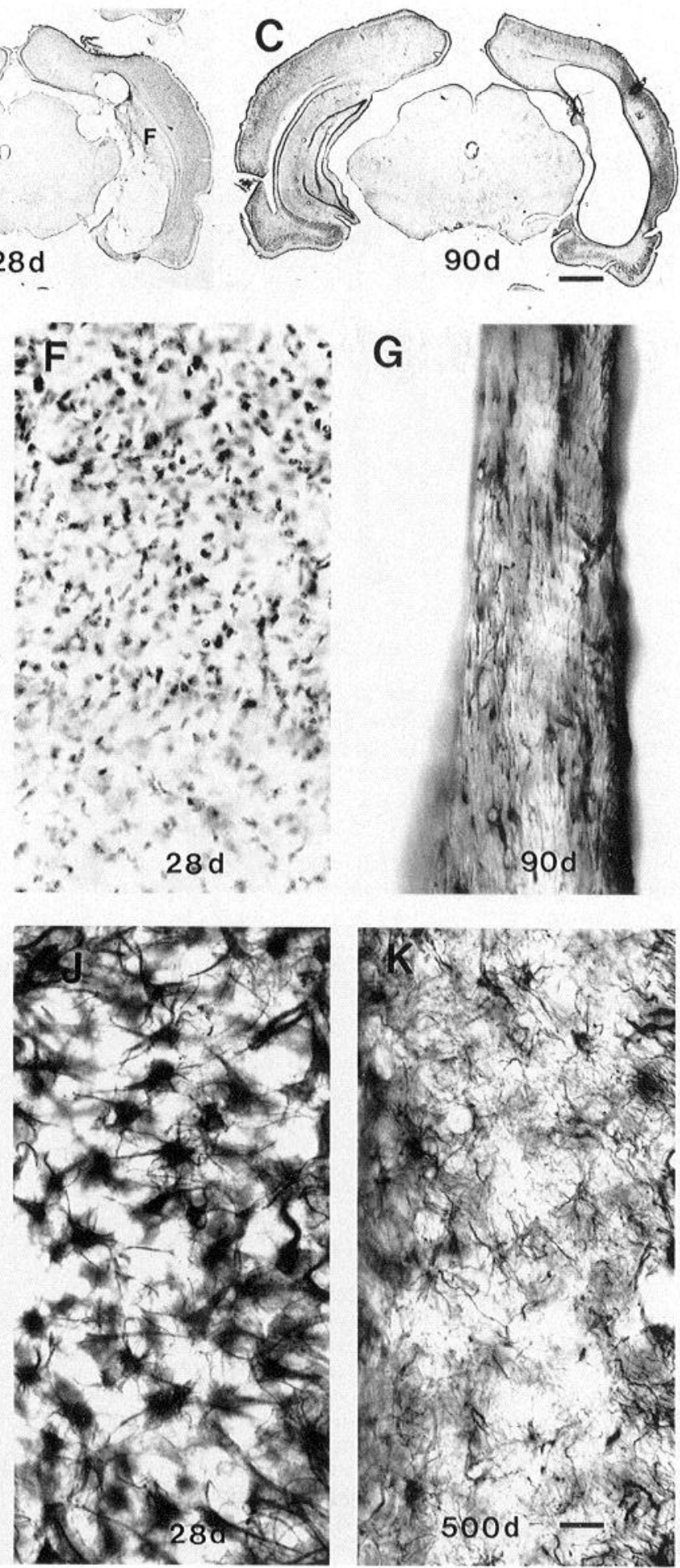

Figure 1. Histological appearance of hippocampal tissue at various times after unilateral NMDA lesions. $A-C$, Survey photomicrographs of Nisslstained sections through the rat hippocampal formation and midbrain at $7 \mathrm{~d}(A), 28 \mathrm{~d}(B)$, and $90 \mathrm{~d}(C)$ after multiple unilateral injections of NMDA into the hippocampus. Note the massive disruption of hippocampal cytoarchitecture at 7 and $28 \mathrm{~d}$ and that only a thin band of tissue consisting largely of a remnant of white matter from the fimbria is present at $90 \mathrm{~d}$. $D-F$, Details of $A$ and $B$ showing the appearance of hippocampal neurons in the unlesioned or control $(c o n)$ side $(D)$ and on the lesioned side the absence of neurons and presence of considerable gliosis at $7 \mathrm{~d}(E)$ and $28 \mathrm{~d}(F)$ after NMDA injections. $G-K$, Details of GFAP-stained sections through the hippocampus on the unlesioned side $(H)$ and lesioned side at $7 \mathrm{~d}(I), 28 \mathrm{~d}(J), 90 \mathrm{~d}(G)$, and $500 \mathrm{~d}(K)$ after NMDA injections. $H-J$ are taken from sections neighboring those shown in $D-F$; note the presence of many large reactive astrocytes in the lesioned hippocampus at 7 and $28 \mathrm{~d}$. $G$ is taken from the hippocampal remnant in a section neighboring to that shown in $C$; note that after $90 \mathrm{~d}$ the thin fimbrial white matter remnant contains some GFAP-positive elements but few if any obvious large reactive astrocytes. $K$ is from taken from case R1534 (from a section neighboring that shown in Fig. $6 C$ ) and shows that while some GFAP-positive elements remain in a small remnant of hippocampal tissue after $500 \mathrm{~d}$, the astrocytes are not as large or as darkly stained as at 28 d. Scale bars: $A-C, 1800 \mu \mathrm{m} ; D-K, 25 \mu \mathrm{m}$. 

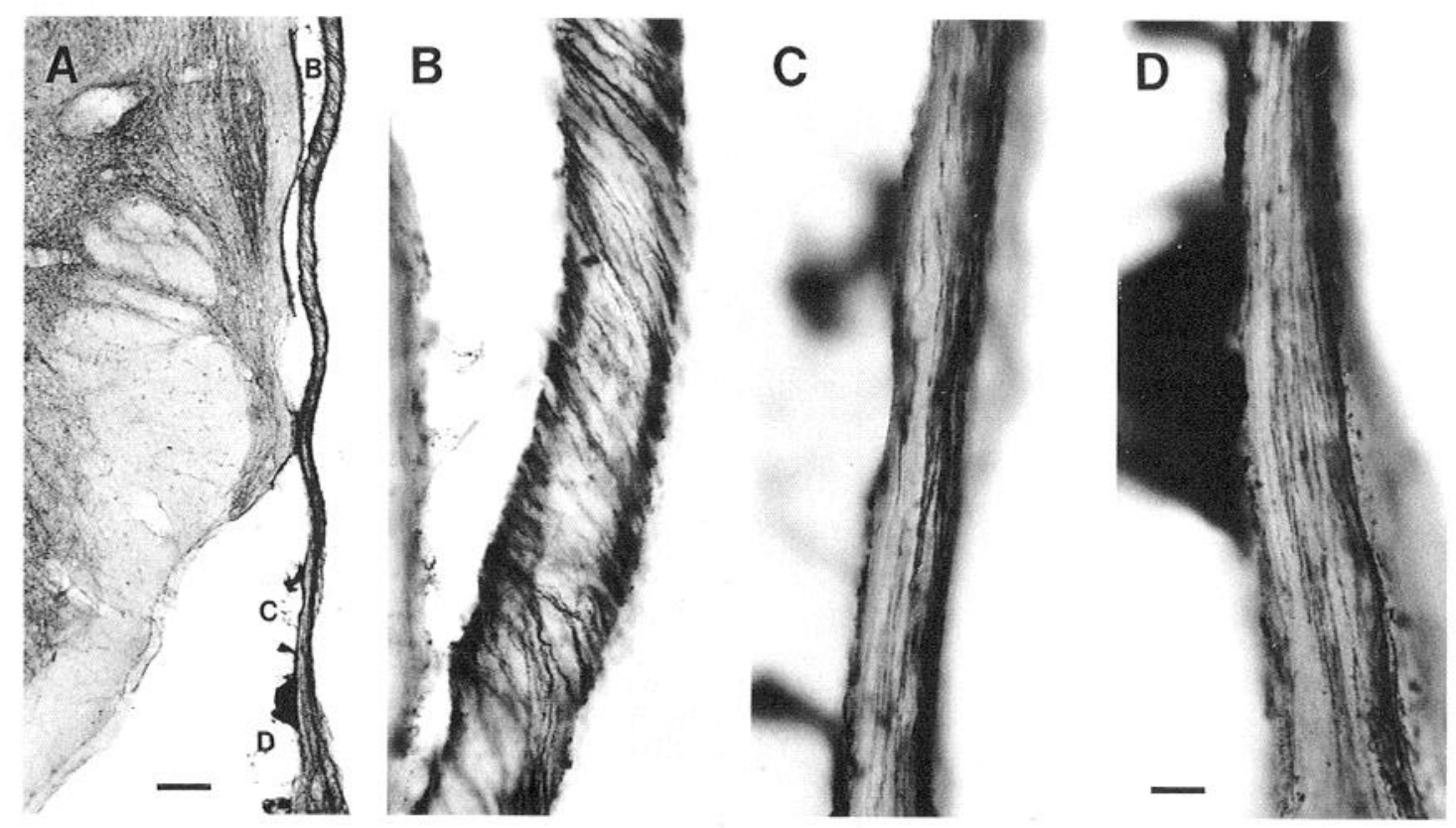

Figure 2. Cholinergic fibers in the hippocampal remnant $500 \mathrm{~d}$ after NMDA lesions. $A$, Survey photomicrograph of an AChE-stained section from case R1534 taken from a section neighboring that shown in Figure $6 C$. In this case, the survival time was $500 \mathrm{~d}$ after unilateral hippocampal NMDA lesions. $B-D$, Details of $A$ showing AChE-positive cholinergic fibers along the entire length of the thin remnant of fimbrial white matter that persisted after the NMDA lesions. Scale bars: $A, 250 \mu \mathrm{m} ; B-D, 25 \mu \mathrm{m}$.

changes were noted in the levels NGF protein in the septal region after unilateral hippocampal ablation, we felt it necessary to compare absolute counts obtained on each side of the medial septal nucleus across all experimental groups, rather than comparing ratios of the left (treated) versus right (untreated) sides as done in previous studies. This required precise matching of septal levels for morphometric determinations. Since cell loss is most pronounced in the caudal septum after FF transection (Sofroniew and Isacson, 1988), cell counts were performed on three pairs of sections stained for ChAT or p $75^{\mathrm{NGFR}}$ taken from a standardized caudal portion of the medial septum between 200 and $1000 \mu \mathrm{m}$ rostral to the decussation of the anterior commissure. Measurements were restricted to this region because we have also previously shown that there is no rostrocaudal shrinkage of the medial septal nucleus after NMDA lesions of the ipsilateral hippocampus, which might influence morphometric values in this region (Sofroniew et al., 1990). Values for cell counts were expressed for individual animals as the mean number

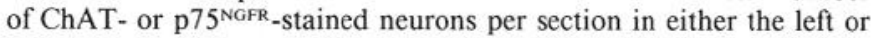
right sides of the medial septal nucleus. The left side was always ipsilateral, and the right side always contralateral to the treated hippocampus. All cell counts were Abercrombie (1946) corrected. Values for cell size were expressed for individual animals as the mean cross-sectional area of ChAT- or p75 $5^{\mathrm{NGFR}}$-stained neurons in either the left or right sides of the medial septal nucleus. Due to the variability of immunohistochemical staining intensity in reactions conducted at different times with different reagents, all optical density measurements were taken as measurements of the left and right medial septal nuclei within the same sections and expressed as a percentage of the left (lesioned) versus the right (unlesioned) side. Optical density values from the treated, left $(L)$, and untreated, right $(R)$ sides were expressed as the percentage of the left versus the right side (i.e., $L / R \times 100)$ for each animal. The significance of differences between experimental groups was tested by ANOVA with post hoc Newman-Keuls pairwise analysis.

\section{Results}

Histological changes in the hippocampal region resulting from the excitotoxic ablation of local neurons

Injections of vehicle had no obvious effect on Nissl-stained neurons or AChE-stained fibers in the hippocampus but did cause a moderate increase in the number of GFAP-positive, reactive astrocytes between 7 and $28 \mathrm{~d}$. In well-lesioned cases, virtually all neurons within the hippocampus and related regions were ablated on the injected side, including neurons in the $\mathrm{CA}$ subfields, dentate gyrus, most of the subiculum, and some parts of the entorhinal cortex. By $7 \mathrm{~d}$ after NMDA injection, neurons were absent and there was massive gliosis with many GFAPpositive astrocytes (Fig. $1 A, D, E, H, I$ ). At $28 \mathrm{~d}$, gliosis was still prominent but considerable tissue shrinkage had occurred (Fig. $1 B, F, J)$. At $90 \mathrm{~d}$, or longer tissue shrinkage was very severe (Figs. $1 C, G ; 3$ ), with only a thin band of white matter persisting as the remnant of the fimbria along its entire rostrocaudal extent in the virtual absence of overlying hippocampal tissue (Fig. $1 C, G)$. Within this tissue remnant, AChE fibers and a few GFAPpositive astrocytes remained even in the smallest of tissue remnants for up to $500 \mathrm{~d}$ (Figs. $1 G, K, 2 A-D$ ). Bilateral surface area measurements were made at equivalent hippocampal levels in Nissl-stained sections. At survival times greater than $90 \mathrm{~d}$, values ranged from less than $10 \%$ to over $80 \%$ tissue present in the lesioned regions as compared with the unlesioned side. These values were correlated with morphometric parameters of septal cholinergic neurons in the same animals.

\section{Effects of excitotoxic ablation of hippocampal neurons on $m R N A$ levels for NGF, BDNF, and NT3 in the hippocampus and related structures}

Quantitative Northern blot analysis showed that injection of vehicle caused a significant $33 \%$ increase in relative levels of mRNA for NGF but not BDNF as compared with values from control (i.e., untreated) animals (Fig. 3). In animals injected with NMDA, hippocampal lesions were recorded as complete or incomplete on the basis of appearance and wet weight. In animals with complete hippocampal lesions equivalent to those shown in Figure 1, mean relative levels of mRNA for NGF and BDNF in the hippocampal remnant fell significantly to $65 \%$ and $44 \%$ of control values by $7 \mathrm{~d}$, to $22 \%$ and $10 \%$ of control values by $28 \mathrm{~d}$, and to $9 \%$ and $3 \%$ of control values by $300 \mathrm{~d}$ (Fig. 3). In animals with complete hippocampal lesions, relative levels of mRNA for NT3 declined similarly (Fig. $4 A, B$ ). In animals with 


\section{NGF mRNA in Hippocampus}

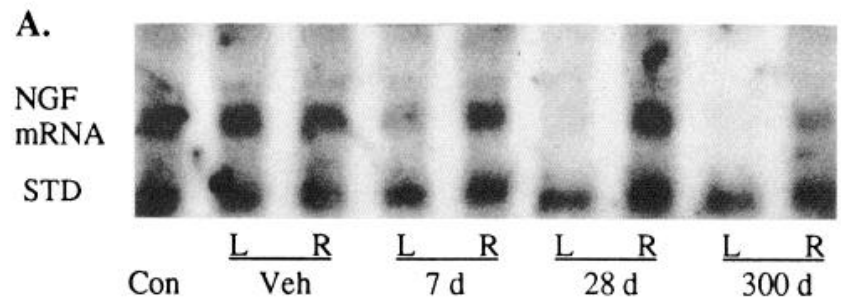

B.

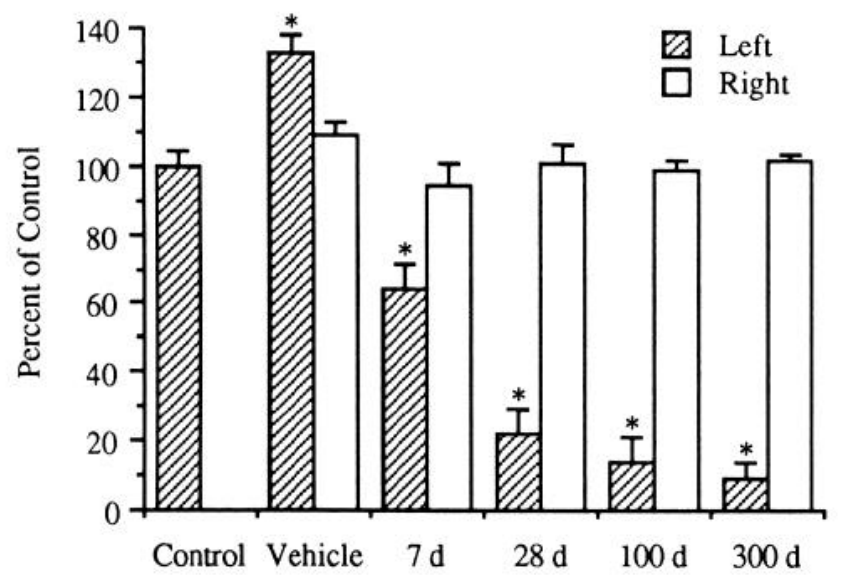

BDNF mRNA in Hippocampus

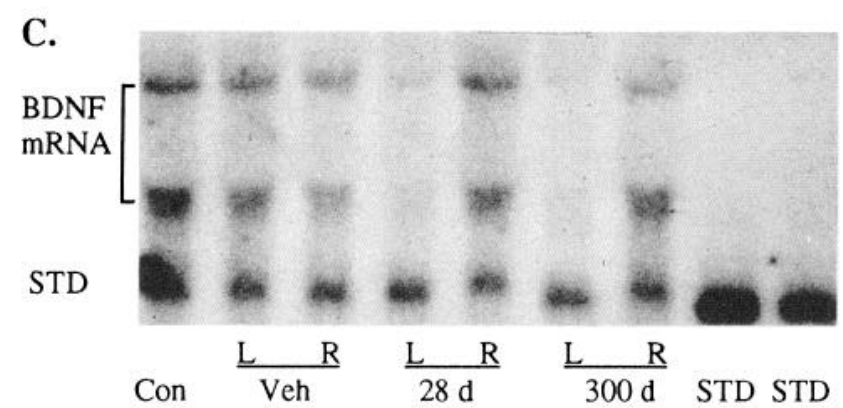

D.

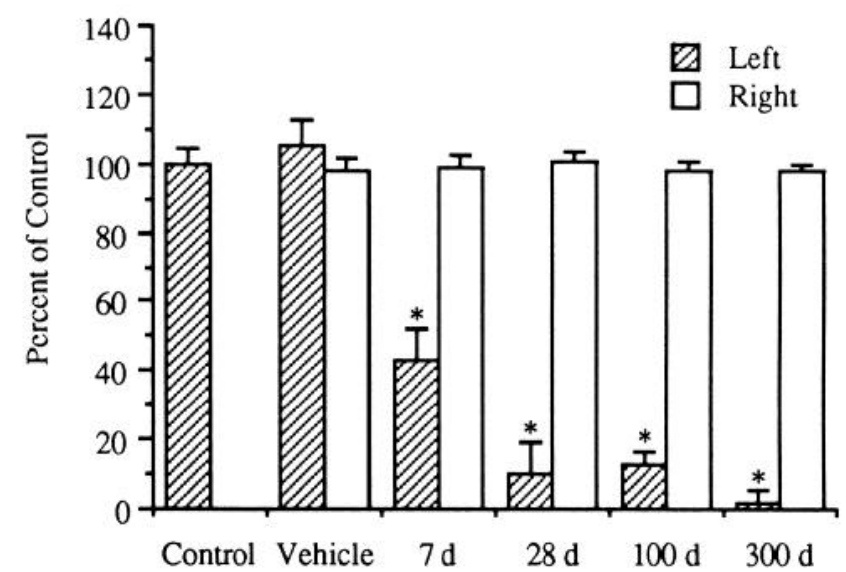

Figure 3. NGF and BNDF mRNA in the hippocampus at various times after unilateral NMDA lesions. $A$ and $C$, Northern blot analysis of mRNA for NGF $(A)$ and BDNF $(C)$ at various time points after injection of NMDA or vehicle $(V e h)$ into the hippocampus unilaterally on the left side $(L)$. Con, control (untreated animal); $L$, left (lesioned) side; $R$, right (unlesioned) side. $S T D$, standard added to each sample to assess mRNA recovery during extraction; unextracted standard levels are shown in the two right lanes of $C$. $B$ and $D$, Quantitative analysis by densitometry of NGF $(B)$ and BDNF $(D)$ mRNA. Injection of vehicle (left side) significantly increased NGF but not BDNF mRNA levels after $7 \mathrm{~d}(n=3)$. In animals with complete unilateral hippocampal lesions, relative levels of mRNA for NGF in the hippocampal remnant (left side) fell significantly after $7 \mathrm{~d}$ to about $65 \%$ of control values, and declined further to, respectively, $22 \%, 14 \%$, and $9 \%$ of control values by 28,100 , and $300 \mathrm{~d}\left[F_{(5,22)}\right.$ $=346.5$ ]. Moreover, post hoc Newman-Keuls pairwise analysis showed that this decline was significantly progressive such that control $>7 \mathrm{~d}>$ $28 \mathrm{~d}>100 \mathrm{~d}=300 \mathrm{~d}, p<0.01$ at each step ( $n=4$ per group). In animals with complete unilateral hippocampal lesions, relative levels of mRNA for BDNF in the hippocampal remnant (left side) had fallen significantly after $7 \mathrm{~d}$ to about $44 \%$ of control values, and declined further to, respectively, $10 \%, 14 \%$, and $3 \%$ of control values by 28,100 , and $300 \mathrm{~d}\left[F_{(5,22)}=346.5\right]$. Post hoc Newman-Keuls pairwise analysis showed that this decline was significantly progressive such that control $>7 \mathrm{~d}>28 \mathrm{~d}=100 \mathrm{~d}>300 \mathrm{~d}, p<0.01$ at each step $\left(n=4\right.$ per group). ${ }^{*}, p$, versus control, ANOVA.

partial lesions, relative neurotrophin mRNA levels appeared partially reduced (Fig. $4 A$ ); these samples were not quantitatively compared.

To look for a possible compensatory upregulation in NGF or $\mathrm{BDNF}$ production in the three principle brain regions to which septal cholinergic neurons might send collateral projections, mRNA levels were determined in the ipsilateral entorhinal and cingulate cortices, and in the contralateral hippocampus. In control animals, relative mRNA levels for NGF and BDNF were considerably lower in the entorhinal and cingulate cortex than levels found in the hippocampus (not shown). In animals with complete ablation of hippocampal neurons, but with no obvious damage to the entorhinal or cingulate cortices, relative mRNA levels for NGF (not shown) and BDNF were not elevated in either the entorhinal (Fig. $4 C, D$ ) or cingulate cortex (not shown) and were indistinguishable from control levels in both the ipsilateral and contralateral sides. In the hippocampus contralateral to NMDA lesions, neurotrophin mRNA levels were indistinguishable from normal (i.e., control) levels (Figs. 3, 4)

\section{Effects of excitotoxic ablation of hippocampal neurons or FF transection on ELISA measurements of NGF protein in the septal region}

To estimate the amount of NGF protein that might be present within septal cholinergic neurons after retrograde transport from the hippocampus, the level of NGF present in the septal region was measured by ELISA. Methods sensitive enough to detect other neurotrophins in septal tissue are not yet available. Due to limitations in the precision with which the septal region can be dissected, the resulting tissue blocks contained not only cholinergic neurons of the medial septal nucleus, but also cholinergic neurons of the VDB and HDB (Fig. $5 A$ ). In animals with complete hippocampal lesions, NGF protein levels in the ipsilateral septal region fell significantly, to about $35 \%$ of control values by $28 \mathrm{~d}$, and remained essentially at this level at 100 and $300 \mathrm{~d}$ (Fig. 5B). In these animals, NGF protein levels also declined significantly but not as severely in the contralateral septum (Fig. $5 B$ ). In addition, no signal for NGF or BDNF mRNA 


\section{NT3 mRNA in Hippocampus}

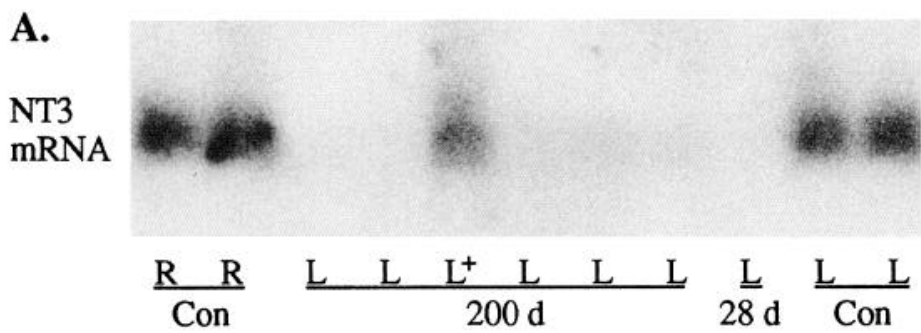

B.

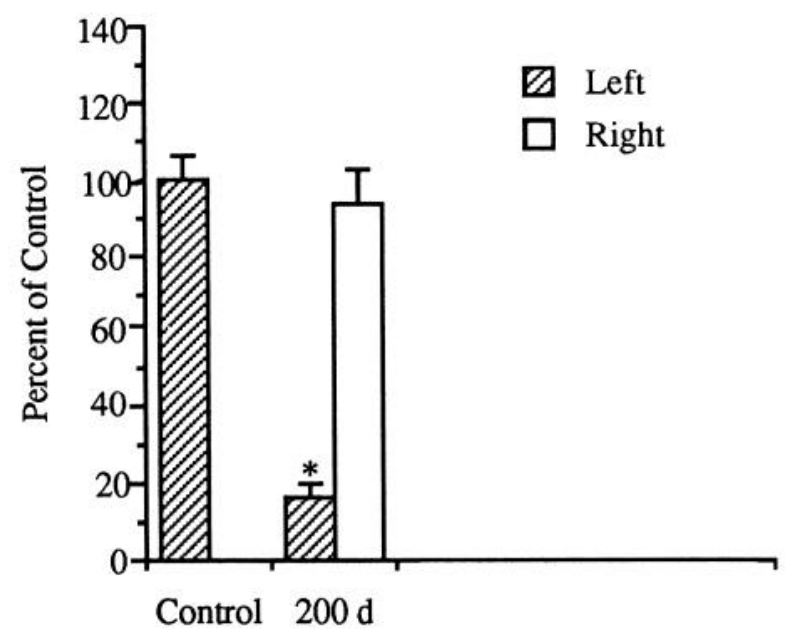

\section{BDNF mRNA in Entorhinal Cortex}

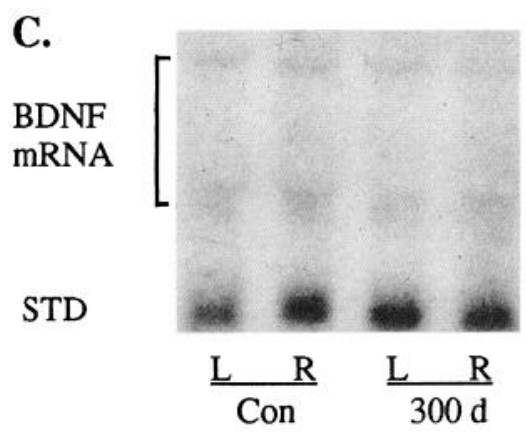

D.

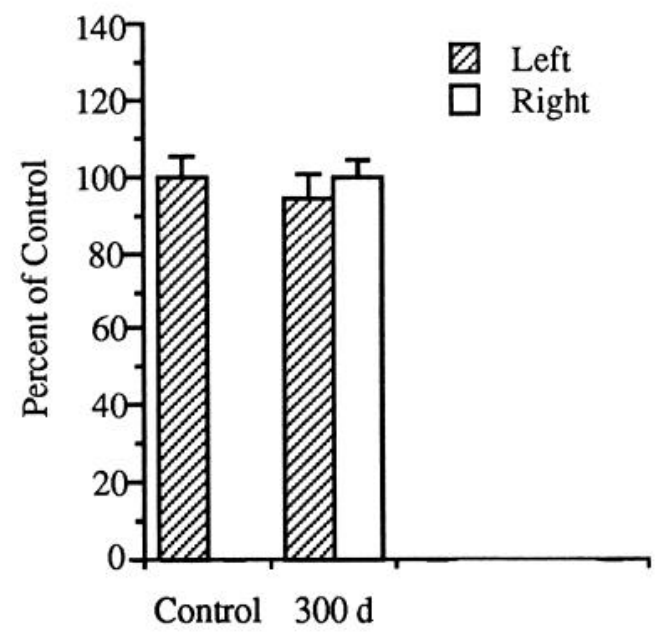

Figure 4. NT3 mRNA in the hippocampus and BDNF in the entorhinal cortex after unilateral NMDA lesions. $A$, Northern blot analysis of mRNA for NT3 at 28 or $200 \mathrm{~d}$ after injection of NMDA into the hippocampus unilaterally on the left side $(L)$. The + symbol denotes a tissue sample described at the time of dissection as incompletely lesioned, with about $60 \%$ of the hippocampal tissue remaining. Note that NT3 mRNA levels were only partially reduced in this sample and it was not included in calculation of the mean value for the group. B, Quantitative analysis by densitometry of NT3 mRNA. In animals with large unilateral hippocampal lesions, relative levels of mRNA for NT3 in the hippocampal remnant (left side) had fallen significantly by $200 \mathrm{~d}$ to $17 \%$ of control values; ${ }^{*}, p<0.001$ versus control (ANOVA; $n=5$ per group). $C$, Northern blot analysis of mRNA for BDNF in the entorhinal cortex at $300 \mathrm{~d}$ after injection of NMDA into the hippocampus unilaterally on the left side $(L)$. D, Quantitative analysis by densitometry of BDNF mRNA in the entorhinal cortex. Hippocampal NMDA lesions did not significantly change BDNF mRNA in the entorhinal cortex ipsilateral or contralateral to the lesion (ANOVA) ( $n=4$ per group). Con, control (untreated animal); $L$, left (lesioned) side; $R$, right (unlesioned) side. $S T D$, standard (synthetic shorter fragment of BDNF mRNA added to each sample).

was detectable in the septal region of control animals or at any survival time after ipsilateral hippocampal ablation (data not shown).

Since axotomy of the dorsal septohippocampal pathway by complete transection of the FF causes a loss of cholinergic neurons from the medial septum (O'Brien et al., 1990; Tuszynski et al., 1990), NGF protein levels were also measured in animals with lesions of this kind. NGF protein levels were not significantly different from control values in either the ipsilateral or contralateral septum $28 \mathrm{~d}$ after complete transection of the FF (Fig. 5B).

\section{Effects of excitotoxic ablation of hippocampal neurons or FF transection on morphometric parameters of immunohistochemically identified septal cholinergic neurons}

Septal cholinergic neurons from five experimental groups of animals were compared qualitatively by morphometric analysis: (1) animals that received unilateral injections of vehicle to the hippocampus, (2) animals surviving $28 \mathrm{~d}$ after axotomy of the septohippocampal pathway by complete unilateral transection of the FF, (3) animals surviving 90-120 d after complete unilateral ablation of the hippocampus available from a previous study (Sofroniew et al., 1990), (4) animals with NMDA lesions of the hippocampus after survival times of 360-500 d, and (5) animals with NMDA lesions that included both the hippocampal formation and entorhinal cortex.

The number, size, and staining intensity of septal cholinergic neurons stained for ChAT or p $75^{\text {NGFR }}$ were determined and correlated individually with the amount of hippocampal tissue present (measured as surface area) for each animal for regression analysis. In addition, mean values were compared from different groups. Because hippocampal neurons were not completely ablated by NMDA lesions in all cases, animals were included in the group comparisons only if the hippocampal remnant on the lesioned side exhibited a surface areas of less than $10 \%$ of the unlesioned side (Fig. 6A-D). At survival times greater than 
12 weeks after excitotoxic lesions, the surface area of cortical areas is roughly proportional to the number of surviving neurons (Isacson and Sofroniew, 1992). Similarly, animals that received NMDA injections to the both the hippocampus and entorhinal cortex were included in group comparisons only if the remnants of the hippocampus and the entorhinal cortex on the lesioned side were, respectively, less than $10 \%$ and $15 \%$ of the unlesioned side.

Cell number. In animals that received injections of vehicle unilaterally to the hippocampus approximately equal numbers of either ChAT or $\mathrm{p} 75^{\mathrm{NGFR}}$ stained neurons were found on both sides of the medial septal nucleus (Fig. 7A,B). Complete unilateral FF transection caused a significant drop by over $75 \%$ in the number of ChAT-and $\mathrm{p} 75^{\mathrm{NGFR}}$-stained neurons ipsilaterally, but no change contralaterally, as compared with vehicle-injected animals (Fig. 7A,B). No significant difference was found in the number of ipsi- or contralateral ChAT- or $p 75^{\text {NGFr }}$-stained neurons $90-120 \mathrm{~d}$ after complete unilateral ablation of the hippocampus alone or after complete ablation of both the hippocampus and entorhinal cortex (Fig. 7A,B). However, 360-500 d after complete unilateral ablation of the hippocampus we found a significant $30 \%$ decrease in the number of ipsilateral ChATstained, but not $\mathrm{p} 75^{\mathrm{NGFR}}$-stained neurons, with no changes in the number of neurons stained for either marker contralaterally (Figs. 6, 7A,B). Regression analysis showed no correlation between the amount of hippocampal tissue present and the number of ipsilateral septal neurons stained for either ChAT or p $75^{\text {NGFR }}$ in vehicle-injected animals and all animals with hippocampal lesions regardless of lesion size after survival times of $120 \mathrm{~d}$ or less. However, a highly significant correlation was found between amount of hippocampal tissue present and the number of ipsilateral ChAT-stained, but not p $75^{\mathrm{NGFR}}$-stained, neurons after survival times of 360-500 d (Fig. 7C-F).

Cell size. In animals that received injections of vehicle unilaterally to the hippocampus, mean cross-sectional areas for both ChAT- and p $75^{\mathrm{NGFR}}$-stained neurons were essentially the same on either side of the medial septal nucleus (Fig. $8 A, B$ ). After complete unilateral ablation of the hippocampus, the mean cross-sectional areas of both ChAT- and p $75^{\mathrm{NGFR}}$-stained neurons in the ipsilateral medial septum were significantly reduced by about $30 \%$ as compared with vehicle-injected animals, regardless of survival time (Figs. 6, 8A). The additional ablation of the entorhinal cortex did not increase this degree of shrinkage further (Fig. 8A,B). Regression analyses of vehicle-injected animals and all animals with hippocampal lesions regardless of lesion size showed that the amount of hippocampal tissue present correlated significantly with the mean cross-sectional area of ipsilateral septal neurons stained for either ChAT or p75 $5^{\mathrm{NGFR}}$ after survival times of either $90-120$ or $360-500 \mathrm{~d}$ (Fig. 8C-F).

Staining intensity. For technical reasons (see Materials and Methods), values for staining intensity were expressed for individual animals as the ratio of the optical density for either ChAT- or p75 $5^{\text {NGFR }}$-stained neurons in the left versus right sides of the medial septal nucleus (i.e., $L / R \times 100$ ). In animals that received injections of vehicle unilaterally to the hippocampus, the optical density of either ChAT- or p75 $5^{\text {NGFR }}$-stained neurons was essentially the same on both sides of the medial septal nucleus (Fig. 9A). Significant reductions of about 10\% were found in the mean optical density of both ChAT- and p $75^{\text {NGFr }}$ stained neurons in the ipsilateral medial septum as compared with contralateral side after complete ablation of the hippocampus after 90-120 d (Fig. 9A). A smaller but still significant de-

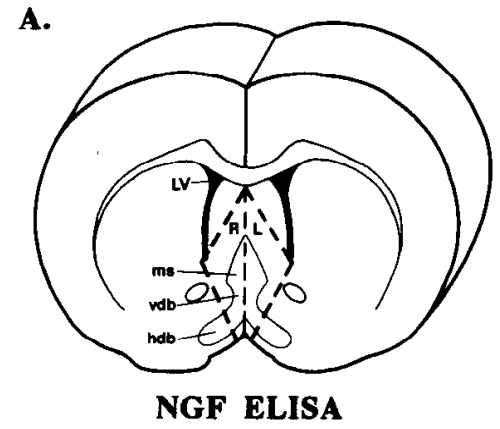

B.

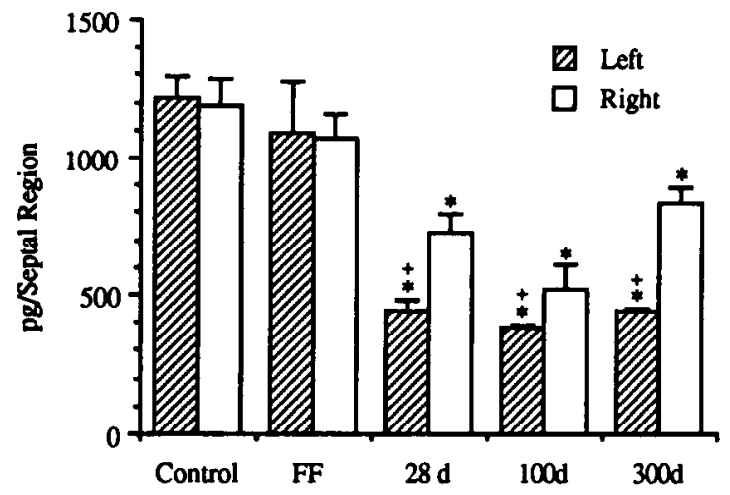

Figure 5. ELISA of NGF in the medial septum after unilateral ablation of the hippocampus with NMDA. $A$, Schematic drawing of the major structural landmarks used to dissect tissue blocks of the septal region from approximately $2-\mathrm{mm}$-thick frontal sections extending rostrally from the decussation of the anterior commissure. Diamond-shaped blocks were cut as indicated by the dashed lines. $L$ and $R$, left and right halves of the tissue block; $L V$, lateral ventricles; $m s$, medial septal nucleus; $v d b$ and $h d b$, vertical and horizontal limbs of the diagonal band nucleus. $B$, Quantitative values of ELISA determinations of NGF protein in the left and right septal region of controls (i.e., untreated animals; $n=4$ ), $28 \mathrm{~d}$ after complete transection of the left fimbria-fornix $(F F)(n=4)$, and $28(n=4), 100(n=3)$, or $300 \mathrm{~d}(n=3)$ after complete hippocampal NMDA lesions on the left side. NGF protein levels did not change significantly in the septal region after FF lesions, but were significantly reduced as compared with control values on both the ipsilateral and contralateral sides at 28,100 , and $300 \mathrm{~d}$ after unilateral hippocampal NMDA lesions (ANOVA). In NMDA-lesioned animals, the decline in NGF levels was significantly greater on the ipsilateral (left) side versus the contralateral (right) side at all time points $\left[F_{(1.9)}=41.02\right]$, whereas the difference in NGF values on the same sides (i.e., left vs left and right vs right) at different time points was not significant. ${ }^{*}, p<0.001$ versus control values on the same side (ANOVA with Newman-Keuls pairwise analysis);,$+ p<0.001$ versus the contralateral side (ANOVA).

cline in optical density was found for ChAT- but not p75 $5^{\text {NGFR }}$ stained neurons at 360-500 d (Fig. 9A). Regression analyses of vehicle-injected animals and all animals with hippocampal lesions regardless of lesion size showed that the amount of hippocampal tissue present correlated significantly with the optical density of ipsilateral septal neurons stained for either ChAT or p $75^{\text {NGFR }}$ after survival times of $90-120 \mathrm{~d}$, but only for ChAT after $360-500 \mathrm{~d}$ (Fig. $9 B-E$ ).

\section{Discussion}

In this study we have shown that basal forebrain cholinergic neurons atrophy severely, but do not die, after excitotoxic lesions that (1) ablate nearly all of their target neurons; (2) reduce target production of mRNA for NGF, BNDF, and NT3 to negligible levels; and (3) lead to a substantial decline in NGF protein levels in the septal region. These findings indicate that in adult 

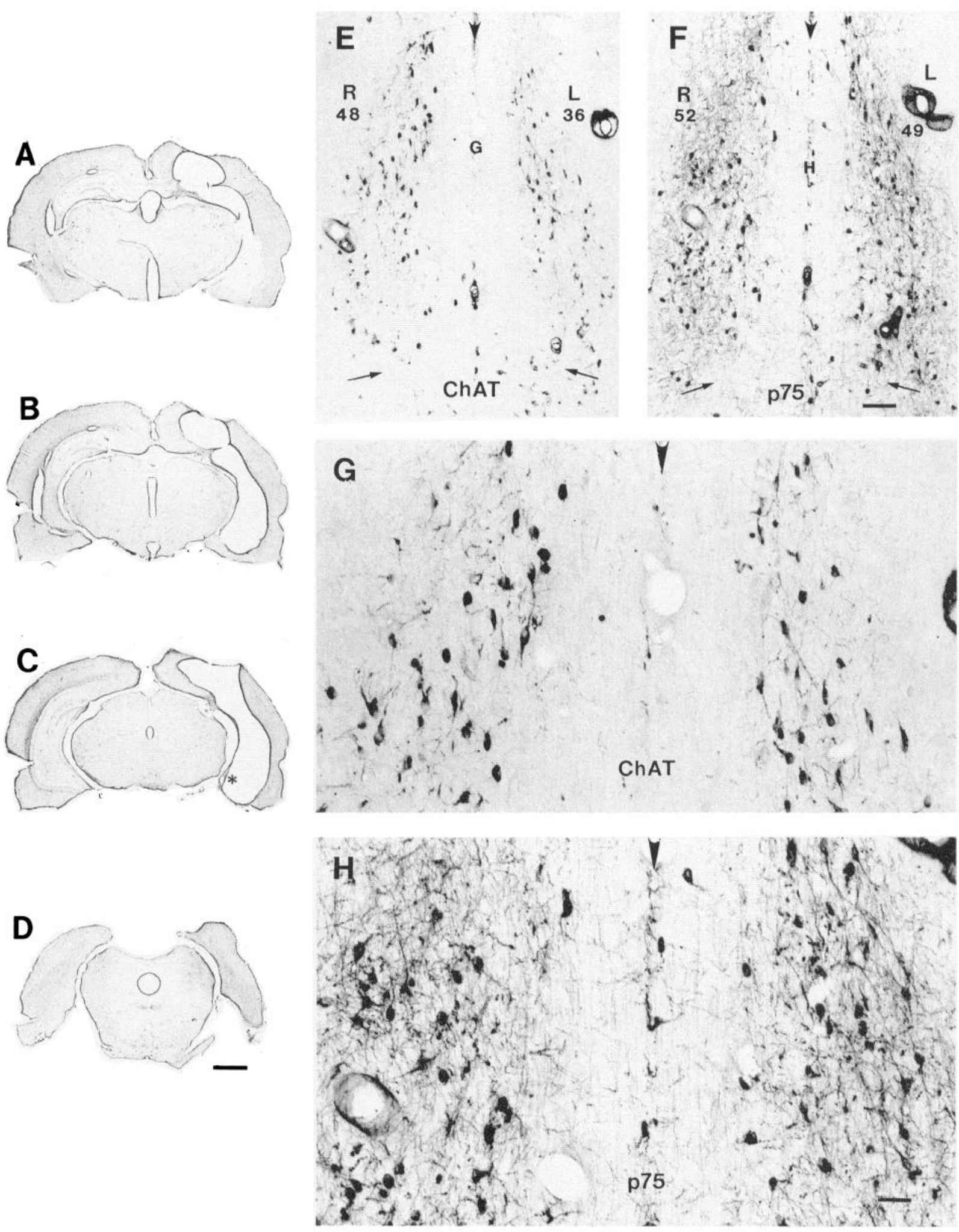

Figure 6. Histologic appearance of septal cholinergic neurons $500 \mathrm{~d}$ after complete unilateral ablation of the hippocampus with NMDA (case R1534). $A-D$, Survey photomicrographs of a series of Nissl-stained frontal sections through the bilateral hippocampal formation at four rostrocaudal levels from case R1534. Note that on the lesioned (left) side, the hippocampus has been reduced to a thin band of white matter as a remnant of the fimbria $(A-C)$, whereas much of the entorhinal cortex remains $(D)$. Asterisk in $C$ denotes a small remnant of hippocampal tissue; a neighboring section through this same remnant stained for GFAP is shown in Figure $1 H$. $E$ and $F$, Photomicrographs of two closely neighboring sections through the septal region of case R1534 immunohistochemically stained for ChAT $(E)$ or p75 NGFR $(F)$. Arrows indicate the ventral boundaries of the medial septal nucleus used for counting purposes. Numbers indicate the Abercrombie corrected cell counts of stained neurons present in the left $(L)$ and right $(R)$ septal nuclei. Note that there has been has been a substantial decline in the number of ChAT-stained, but not p75 $5^{\mathrm{NGFR}}$-stained, neurons in the left septum (which is ipsilateral to the NMDA-lesioned hippocampus) as compared with the unlesioned right side. Arrowheads denote midline. $G$ and $H$, Details of $E$ and $F$, respectively. Note the pronounced shrinkage of both ChAT- and p75 side of the septum ipsilateral to the hippocampal lesion. Arrowheads denote midline. Scale bars: $A-D, 2000 \mu \mathrm{m} ; E$ and $F, 110 \mu \mathrm{m} ; G$ and $H, 45 \mu \mathrm{m}$. 

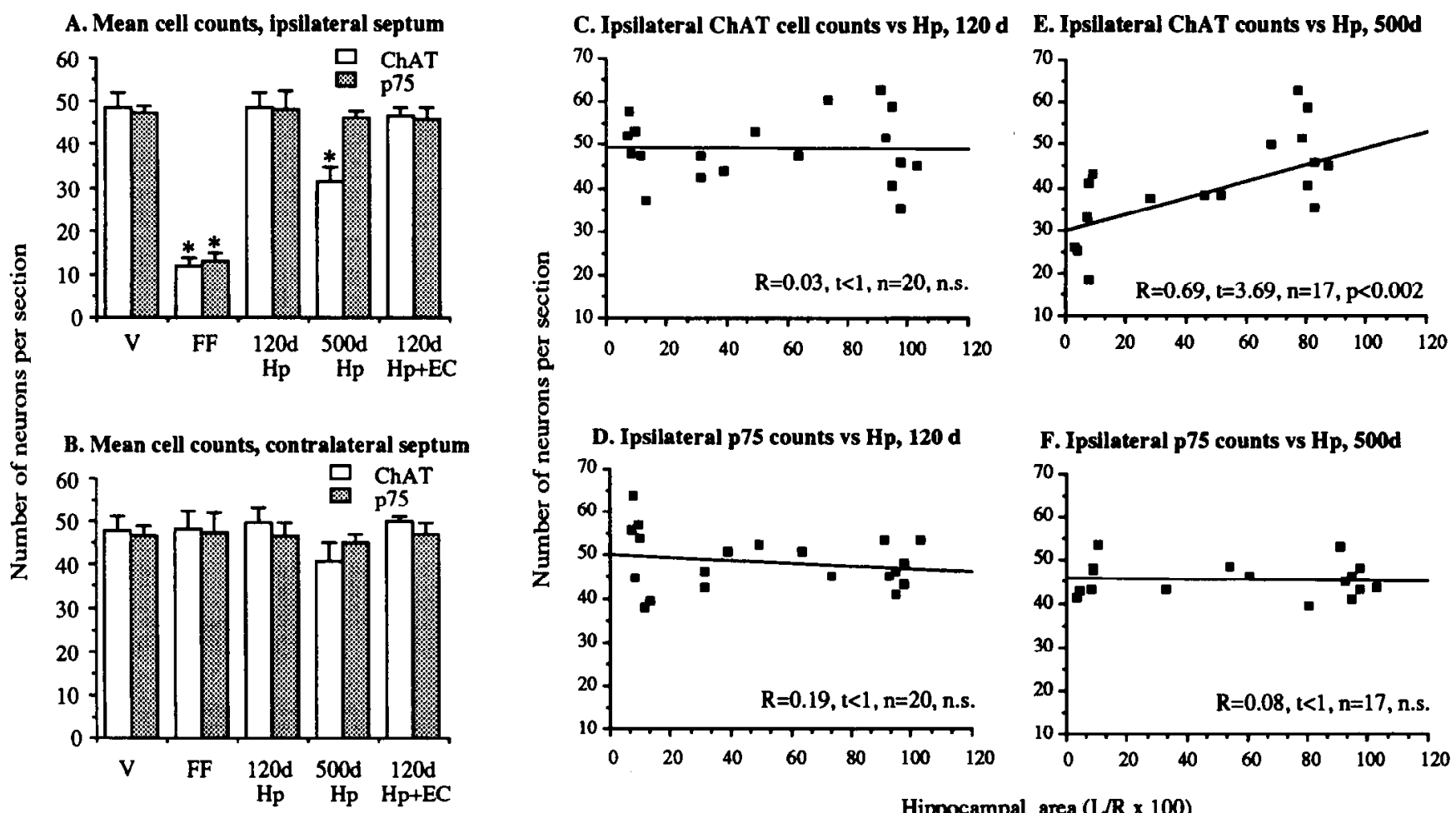

Figure 7. Cell counts of septal cholinergic neurons after unilateral ablation of the hippocampus with NMDA. $A$ and $B$, Mean number of neurons, stained for either ChAT or p75 ${ }^{\text {NGFR }}$, per tissue section in a standardized caudal portion of the medial septal nucleus. The values shown are the means per group of the means per animal of three sections counted for each marker and Abercrombie corrected for the effects of differences in cell size. Values are compared for septal neurons either ipsilateral $(A)$ or contralateral $(B)$ to the cxpcrimentally treated hippocampus. Experimental groups are as follows: unilateral injection of vehicle to the hippocampus $(V, n=7)$; complete unilateral transection of the fimbria-fornix with 28 d survival $(F F, n=6)$; complete ablation of the hippocampus ( $<10 \%$ remaining) with $90-120$ d survival $(120 d \mathrm{Hp}, n=6)$; complete ablation of the hippocampus ( $<10 \%$ remaining) with $360-500$ d survival ( $500 \mathrm{~d} \mathrm{Hp}, n=6)$; complete ablation of both the hippocampus $(<10 \%$ remaining) and entorhinal cortex ( $<15 \%$ remaining) with 90-120 d survival (120d $H p+E C, n=7)$. Two-factor analysis showed no differences between the numbers of ChAT- and p75 ${ }^{\mathrm{NGFR}}$-stained neurons either on the same or opposite sides of the septum in vehicle-injected animals (ANOVA). FF lesions resulted in a significant decline of ipsilateral septal neurons stained for both ChAT and p $75^{\mathrm{NGFR}}\left(t_{4.26}=11.38\right.$ and 12.57 , respectively), while 360-500 d after complete unilateral hippocampal ablation there was a significant decline in the number of ChAT-stained $\left(t_{3.26}=5.44\right)$ but not

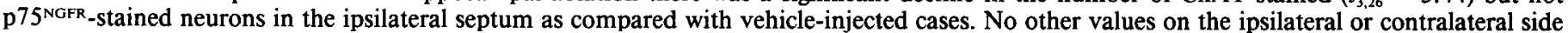
differed significantly from vehicle-injected cases. ${ }^{*}, p<0.001$ versus vehicle-injected cases (ANOVA with Newman-Keuls pairwise analysis). $C$ $F$, Correlation analyses of hippocampal area [expressed as the left (i.e., treated) area divided by the right area $\times 100$ ] versus the mean number of neurons stained either for ChAT or p75 $\mathrm{NGFR}$ in the septum ipsilateral to the treated hippocampus in the same animals. For these analyses, all animals were evaluated that received unilateral injections of vehicle or NMDA to the hippocampus, regardless of the size of the resulting lesion but with survival times of either $90-120 \mathrm{~d}(C, D)$ or 360-500 d $(E, F)$. The only significant correlation shown by regression analysis was that of the number of septal ChAT-stained neurons with amount of ipsilatcral hippocampal area in the $360-500 \mathrm{~d}$ survival group.

rats, target-derived NGF, BDNF, and NT3 do not precisely regulate the survival of septal cholinergic neurons in proportion to the number of target neurons present. Instead, the findings suggest that in the adult, one or more of these target-derived neurotrophins regulate the structural and chemical phenotype of these neurons.

\section{Excitotoxic ablation of local neurons chronically depletes the hippocampal formation of $m R N A$ for $N G F, B D N F$, and NT3}

In situ hybridization studies suggest that the main cellular production sites of mRNA for NGF, BDNF, and NT3 in the uninjured adult hippocampus are neuronal (Ayer-LeLievre, 1989; Phillips et al., 1990; Wetmore et al., 1990). Nevertheless, astrocytes are able to produce NGF in vitro (Lindsay, 1979), and some capacity to produce NGF mRNA persists in the hippocampus at short survival times after the excitotoxic cell death of neurons (Bakhit et al., 1991). Our findings are consistent with these observations. The continued production of NGF and BDNF mRNA in the hippocampus at 7 and $28 \mathrm{~d}$ after NMDA infusion and the gradual reduction in total levels of hippocampal neurotrophin mRNA in parallel with the shrinkage of the lesioned tissue and the resolution of the gliotic reaction suggest that reactive glial cells have the capacity to produce these mRNAs. Nevertheless, by $100 \mathrm{~d}$, relative levels of mRNA for NGF, BDNF, or NT3 were negligible, indicating that widespread excitotoxic ablation of local neurons is an effective means of chronically depleting the capacity of the hippocampal formation to produce NGF, BDNF, and NT3 mRNA.

\section{$N G F$ protein levels decline in the septal region after ablation of hippocampal neurons}

A decline in hippocampal levels of NGF mRNA would be expected to cause a reduction in both NGF synthesis and in the retrograde transport of NGF to the septal region. Our findings are consistent with this conjecture. Excitotoxic lesions that reduced the relative levels of hippocampal NGF mRNA to less than $25 \%$ of control values by $28 \mathrm{~d}$ and to less than $9 \%$ by 300 $\mathrm{d}$ also resulted in a decline to abuut $35 \%$ of control values in 
A. Mean cell area, ipsilateral septum

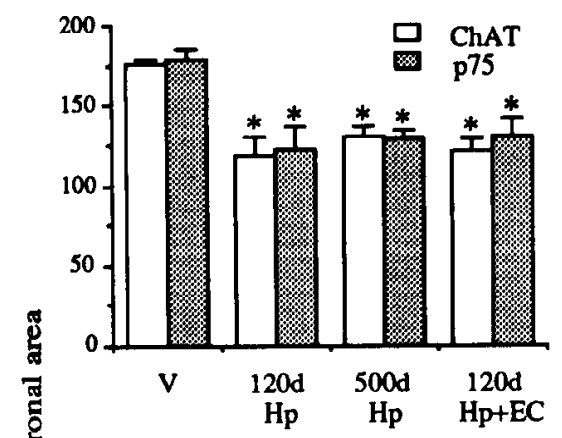

B. Mean cell area, contralateral septum

$\stackrel{0}{\Sigma}$

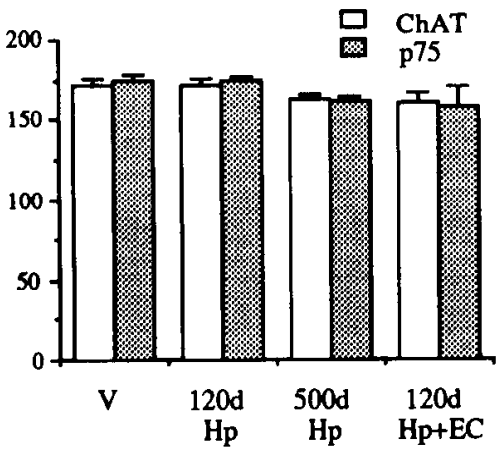

C. Ipsilateral ChAT cell area vs $\mathrm{Hp}, 120 \mathrm{~d}$

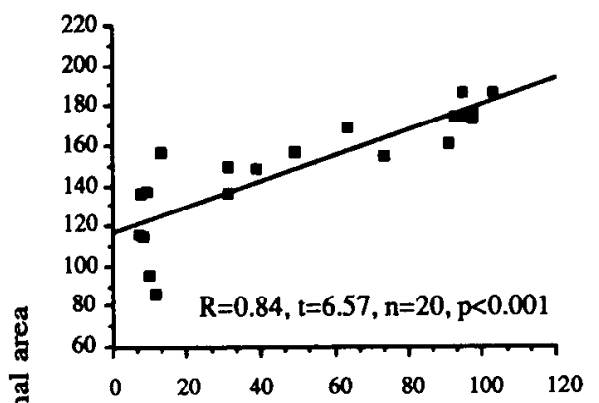

E. Ipsilateral ChAT cell area vs Hp, 500 d

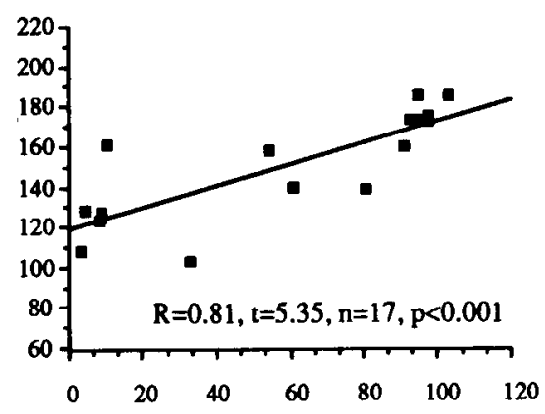

F. Ipsilateral p75 cell area vs $\mathrm{Hp}, 500 \mathrm{~d}$

窟

D. Ipsilateral p75 cell area vs $\mathrm{Hp}, 120 \mathrm{~d}$
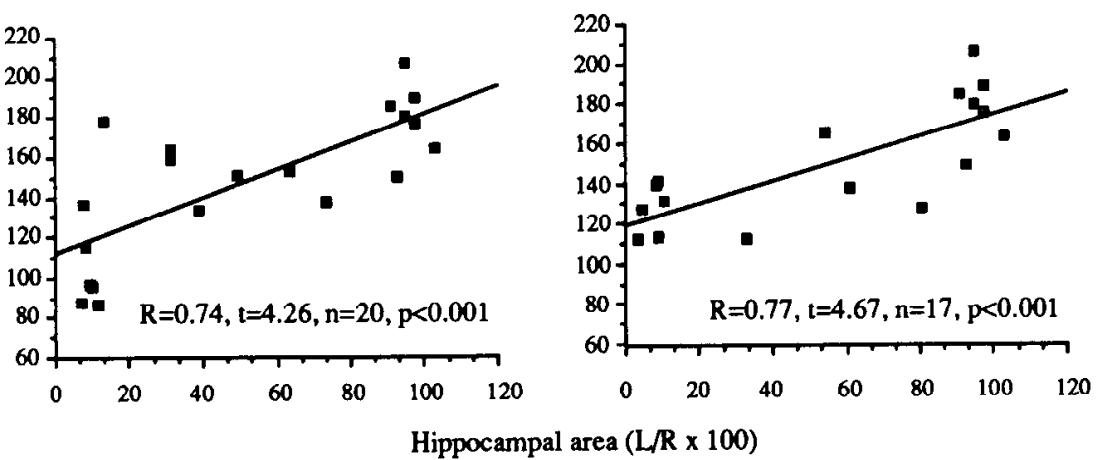

Figure 8. Cell area measurements of septal cholinergic neurons after unilateral ablation of the hippocampus with NMDA. $A$ and $B$, Mean cell areas of neurons stained either for ChAT or p75 NGFR in a standardized caudal portion of the medial septal nucleus. The values shown are the means per group of the means per animal of cells on counted sections. These values are compared for septal neurons either ipsilatcral $(A)$ or contralateral $(B)$ to the experimentally treated hippocampus. Experimental groups are as follows: unilateral injection of vehicle to the hippocampus $(V, n=7)$; complete ablation of the hippocampus ( $<10 \%$ remaining) with $90-120 \mathrm{~d}$ survival $(120 \mathrm{~d} \mathrm{Hp}, n=6)$; complete ablation of the hippocampus (<10\%

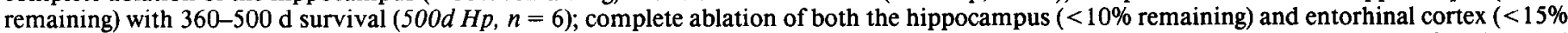
remaining) with 90-120 d survival (120d Hp+EC, $n=7)$. Two-factor analysis showed no differences between the mean cell areas of ChAT- and p75 NGFr -stained neurons either on the same or opposite sides of the septum in vehicle-injected animals (ANOVA). Both ChAT- and p75 ${ }^{\text {NGFR }}$ stained neurons in the ipsilateral septum showed significant and equivalent declines in their mean cell areas at $90-120 \mathrm{~d}\left(t_{4,21}=7.34, t_{2.21}=5.87\right.$, respectively) or $360-500 \mathrm{~d}\left(t_{3,21}=6.89, t_{4,21}=5.31\right.$, respectively) after complete unilateral hippocampal ablation, or $90-120 \mathrm{~d}$ after ablation of the hippocampus and entorhinal cortex $\left(t_{3,21}=4.74, t_{2,21}=4.58\right.$, respectively) as compared with values from vehicle-injected cases. ${ }^{*}, p<0.01$ versus vehicle-injected cases (ANOVA with Newman-Keuls pairwise analysis). $C-F$, Correlation analyses of hippocampal area [expressed as the left (i.e., treated) area divided by the right area $\times 100$ ] versus the mean cell areas of neurons stained either for ChAT or p $75^{\mathrm{NGFR}}$ in the septum ipsilateral to the treated hippocampus in the same animals. For these analyses, all animals were evaluated that received unilateral injections of either vehicle or NMDA to the hippocampus, regardless of the size of the resulting lesion but with survival times of either $120 \mathrm{~d}(C, D)$ or $500 \mathrm{~d}(E, F)$. Regression analysis showed that mean cell areas of both ChAT- and $\mathrm{p} 75^{\mathrm{LNGFR}}$-stained neurons correlated significantly with the ipsilateral hippocampal area in both the 120 and $500 \mathrm{~d}$ survival groups.

the amount of NGF protein detectable in the ipsilateral septal region over the same time period. It is not certain why the decline in NGF protein levels in the ipsilateral septal region was not proportionately as great as the decline in hippocampal mRNA levels, or why the contralateral septal region also showed a significant decline in NGF protein levels to $65 \%$ of control values. NGF might be produced locally and low levels of NGF mRNA have been reported in the septum (Korshing, 1986; Lauterborn et al., 1991). Nevertheless, we were unable to detect NGF mRNA in the septal region of NMDA-lesioned or control rats, making it unlikely that large amounts of NGF were produced in the septum in our rats. A more likely explanation is that the dissected tissue samples of the septal region contained not only the medial septal nucleus but, due to technical limitations, also contained the VDB and part of the HDB. Cholinergic neurons in the VDB and $\mathrm{HDB}$ project not only to the ipsilateral hippocampus, but also to the contralateral hippocampus, olfactory bulb, and cortical regions from which they can derive NGF (Cuello and Sofroniew, 1984). After unilatcral hip- pocampal ablation, ipsilateral VDB and HDB neurons would be expected to continue transporting NGF from these other targcts, so that NGF protein levels in the dissected samples of the ipsilateral septal region would never fall below a certain level, as was observed. In addition, some neurons in the contralateral VDB and HDB would be expected to lose the NGF they were deriving from the ablated hippocampus, thus causing a partial decline of NGF protein levels in the contralateral septal sample, and this too was observed. For these reasons it seems likely that cholinergic neurons in the ipsilateral medial septal nucleus have lost the substantial proportion of their retrogradely derived NGF after unilateral ablation of the hippocampus.

\section{Adult septal cholinergic neurons do not die when deprived of target-derived $N G F, B D N F$, or NT3}

The effect on medial septal cholinergic neurons of the decline in retrograde neurotrophic support resulting from unilateral hippocampal NMDA lesions was investigated by morphometric analysis of the number, size, and staining intensity of these 


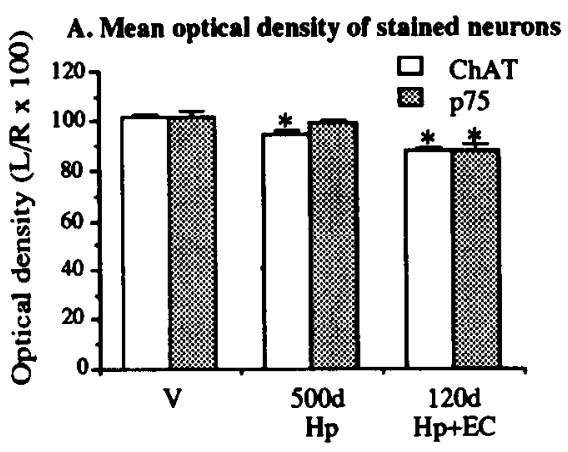

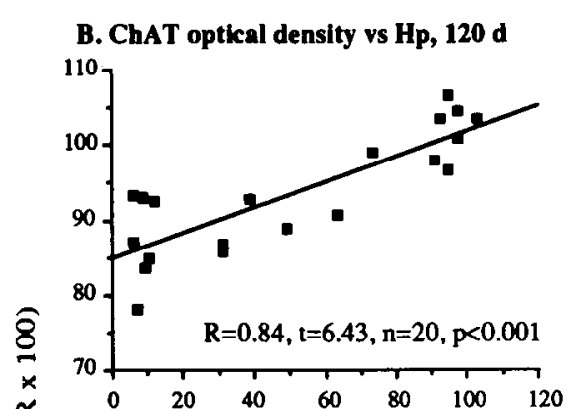

D. ChAT optical density vs $\mathrm{Hp}, 500 \mathrm{~d}$

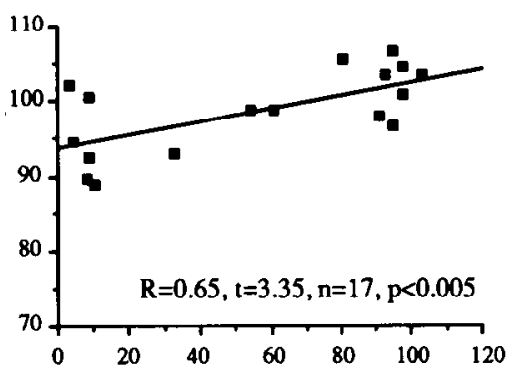

E. p75 optical density vs Hp, 500d

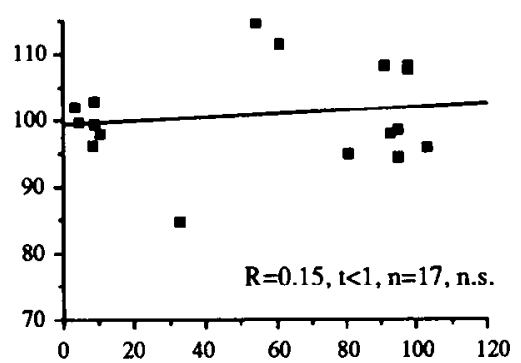

Hippocampal area $(\mathrm{L} / \mathrm{R} \times 100)$

Figure 9. Staining intensity measurements of ChAT and p75 ${ }^{\text {NGFR }}$ in septal cholinergic neurons after unilateral ablations of the hippocampus with NMDA. $A$, Mean optical density measurements of neurons stained either for ChAT or p $75^{\text {NGFr }}$ in a standardized caudal portion of the medial septal nucleus. The values shown are the means per group of the percentage difference (i.e., $L / R \times 100$ ) of the mean optical density of septal neurons ipsilateral (left) or contralateral (right) to the experimentally treated hippocampus per animal. Experimental groups are as follows: unilateral injection of vehicle to the hippocampus $(V, n=7)$; complete ablation of the hippocampus (<10\% remaining) with $360-500 \mathrm{~d}$ survival (500d $\mathrm{Hp}$, $n=6$ ); complete ablation of both the hippocampus (<10\% remaining) and entorhinal cortex $(<15 \%$ remaining) with $90-120 \mathrm{~d}$ survival $(120 d$ $H p+E C, n=7$ ). Optical density values for ChAT-stained neurons were significantly lower ipsilateral to the hippocampal lesions at both $120 \mathrm{~d}$ $\left(t_{3.17}=7.28\right)$ and $500 \mathrm{~d}\left(t_{2.17}=3.64\right)$ and for $\mathrm{p} 75^{\mathrm{NGFR}}$-stained neurons were significantly lower only at $120 \mathrm{~d}\left(t_{3.17}=11.68\right){ }^{*}, p<0.05(\mathrm{ANOVA}$ with Newman-Keuls pairwise analysis). $C$ and $D$, Correlation analyses of hippocampal area [expressed as the left (i.e., treated) area divided by the right area $\times 100$ ] versus the optical density values of septal neurons stained either for ChAT or p75 $5^{\text {NGrR }}$ in the same animals. For these analyses, animals were evaluated that had unilateral injections of vehicle or NMDA to the hippocampus, regardless of the size of the resulting lesion but with survival times of $120 \mathrm{~d}(C, D)$. Regression analysis showed that the optical density values for ChAT-stained neurons correlated significantly with the ipsilateral hippocampal area at $90-120$ and 360-500 d, while the p75 ${ }^{\text {NGFR }}$ optical density correlated significantly with hippocampal area only at $90-120 \mathrm{~d}$.

neurons identified immunohistochemically using two markers, ChAT and the low-affinity NGF receptor, p75 ${ }^{\mathrm{NGFR}}$. Both of these markers label and are confined to cholinergic neurons in the medial septal nucleus (Eckenstein and Sofroniew, 1983; Dawbarn et al., 1988). Cell counts were performed to look for the disappearance of septal neurons as possible evidence of cell death. Two immunohistochemical markers were used because both ChAT and p75 NGFR are dynamically regulated in these neurons (Gage et al., 1989; Higgins et al., 1989) and can be downregulated in other CNS neurons to the disappearance of immunoreactivity in the absence of cell death (Lams et al., 1988; Wood et al., 1990). The presence of neurons stained with either marker was taken as evidence of viable cholinergic cells. In agreement with our previous findings (Sofroniew et al., 1990) and those of Kordower et al. (1992), animals examined 90-120 d after complete ablation of either the hippocampus, or the hippocampus plus entorhinal cortex, showed no significant decline in the mean number of medial septal cholinergic neurons stained for either marker. In animals 360-500 d after complete hippocampal ablation there was also no significant decline in the mean cell number of $\mathrm{p} 75^{\mathrm{NGFR}}$-stained neurons, but the number of neurons stained for ChAT declined significantly by about
$30 \%$. Based on the presence of $\mathrm{p} 75^{\mathrm{NGFR}}$ staining, we conclude that there was no loss of septal cholinergic neurons in the 360$500 \mathrm{~d}$ survival group, but that some of these neurons had downregulated their expression of ChAT to levels where immunoreactivity could not be detected. Thus, even after very long survival times and loss of the vast majority of their target neurons in the ipsilateral hippocampus, there was no evidence of cell death of medial septal cholinergic neurons.

To interpret the implications of our findings for the neurotrophic hypothesis, it is necessary to consider whether these neurons derive additional support from targets other than the hippocampal region via collateral projections. In double labeling experiments, less than $5 \%$ of medial septal neurons were found to project both to the ipsilateral hippocampus and other sites (Sofroniew et al., 1990). The observation that FF transection leads to the death of many of these neurons (O'Brien et al., 1990; Tuszynski et al., 1990) by cutting the pathway to the ipsilateral hippocampus but not to other sites also supports the viewpoint that these neurons do not derive sustaining support from other targets. We also found that after ablation of the hippocampal formation there was no compensatory increase in neurotrophin mRNA levels in other brain regions. Together, 
these findings suggest that most septal cholinergic neurons project only to the ipsilateral hippocampal formation and that lesions ablating hippocampal neurons will deprive septal cholinergic neurons of their sole source of target-derived neurotrophic support. Thus, our finding that septal cholinergic neurons are able to survive even when there is a $90 \%$ reduction in the production of NGF, BDNF, or NT3 mRNA by their target neurons and a greater than $65 \%$ reduction in retrogradely transported NGF suggests that in adult rats, medial septal cholinergic neurons either are not dependent on, or require only trace amounts of, these neurotrophins for survival. Although it could be argued that the cholinergic neurons might be able to derive from some nontarget source sufficient levels of these neurotrophins for survival, the fact that they are unable to do so after FF transection makes this possibility seem unlikely. It also deserves mention that other growth factors such as FGF, CNTF, or NT4 might be produced in the hippocampal remnant after NMDA lesions and keep septal cholinergic neurons alive. Infusions of FGF (Anderson et al., 1988) and CNTF (Hagg et al., 1992) have been reported to prevent the loss of medial septal cholinergic neurons after FF transection. Regardless of whether the septal cholinergic neurons require only trace amounts of their specific neurotrophins, or can survive by deriving support from other growth factors, the survival of these afferent neurons is not regulated by the neurotrophic factors NGF, BDNF, or NT3 in proportion to the number of target neurons present in adult rats.

\section{Cell size and staining intensity of adult septal cholinergic neurons correlate with amount of hippocampal tissue}

Although medial septal cholinergic neurons did not die in response to loss of target-derived trophic support, they underwent severe atrophy in the form of cell shrinkage and loss of staining intensity. The degree of cell shrinkage was similar after survival times of 90-120 and 360-500 d, and was significantly correlated with the amount of neuron-containing hippocampal tissue present. These findings are in agreement with reports that loss of target neurons leads to cell shrinkage of other basal forebrain cholinergic neurons, and that this shrinkage can be prevented by grafts of target neurons (Sofroniew et al., 1986, 1987). Since NGF, BDNF, and NT3 mRNA levels were depleted in animals with hippocampal lesions, our findings suggest that the cell size of medial septal cholinergic neurons may be related to the levels of one or more of these neurotrophins produced by target neurons. Exogenous administration of NGF can regulate the size of basal forebrain cholinergic neurons in vivo and in vitro (Gage et al., 1989; Higgins et al., 1989; Svendsen et al., in press).

Optical density measurements showed significant declines in the staining intensity of both ChAT and $p 75^{\text {NGFR }}$ in septal cholinergic neurons at survival times of 90-120 d, and of ChAT staining at $360-500 \mathrm{~d}$ in animals with hippocampal lesions. The reason for the difference in the staining intensity of $p 75^{\mathrm{NGFR}}$ in the two different survival groups is not certain. Regression analyses showed significant correlations between the amount of neuron-containing hippocampal tissue present and staining intensity of both ChAT and p75 NGFR at 90-120 d, and of ChAT at 360-500 d. Moreover, in animals with 360-500 d survival times after hippocampal lesions, ChAT staining was reduced to the point where it was no longer detectable in $30 \%$ of the neurons that could be stained for $\mathrm{p} 75^{\mathrm{NGFR}}$, suggesting that the septal cholinergic neurons were still viable but had severely downregulated their ChAT expression. Since NGF, BDNF, and NT3 mRNA levels werc depleted in animals with hippocampal le- sions, staining intensity of medial septal cholinergic neurons may be related to the levels of one or more of these neurotrophins produced by target neurons. NGF will upregulate the expression of ChAT and p75 ${ }^{\mathrm{NGFR}} \mathrm{mRNA}$, and of ChAT enzyme activity in basal forebrain cholinergic neurons in vivo (Gnahn et al., 1983; Gage et al., 1989; Higgins et al., 1989), and both NGF and BDNF will increase ChAT activity in septal tissue cultures (Alderson et al., 1990; Knüsel et al., 1990, 1991).

Axotomy of the dorsal septohippocampal pathway does not deplete the septal region of NGF but leads to the loss of septal cholinergic neurons

Axotomy of septal cholinergic neurons by transection of the dorsal septohippocampal pathway in the FF causes massive loss of both ChAT- and p7 $75^{\mathrm{NGFR}}$-immunoreactive neurons as well as considerable neuronal cell death as indicated by the loss of other neuronal markers (O'Brien et al., 1990; Tuszynski et al., 1990) and ultrastructural evidence (Zhou, Svendsen, Cooper, Iversen, and Sofroniew, unpublished findings). The cause of the more severe reaction of septal cholinergic neurons to FF transection than to loss of target-derived neurotrophins is not certain. Axotomy is a physical injury that may trigger as yet unidentified intracellular processes distinct from those caused by loss of neurotrophic support. Alternatively, axotomy might cause a more complete blockade of retrograde transport of trophic factors than does loss of target neurons. We tested this possibility using ELISA measurements and found that septal NGF protein levels did not decline after FF transections, in agreement with previous reports (Gasser et al., 1986). The source of septal NGF after FF transection is not known, but after injury, inflammation and local release of cytokines may trigger NGF synthesis by non-neuronal cells (Lindholm et al., 1987, 1992; Spranger et al., 1990). Regardless of its source, there is more NGF protein in the septal region after FF transection than after ablation of ipsilateral hippocampal neurons. To date there is no compelling evidence suggesting that the more severe reaction of septal cholinergic neurons to axotomy is due to a greater efficiency of axotomy in depriving these neurons of NGF or other retrogradely derived neurotrophic factors. Not only NGF, but also FGF and CNTF can protect septal neurons from axotomy-induced cell death (Anderson et al., 1988; Hagg et al., 1992), even though there is no evidence that these substances are neurotrophic factors in the traditional sense for the neurons that they are protecting. Such observations further support the suggestions that axotomy by FF transection leads to the cell death of medial septal cholinergic neurons by means other than depriving the neurons of target-derived neurotrophic support, and that the survival-promoting effect of NGF on axotomized septal cholinergic neurons is pharmacologic.

\section{Neurotrophins and neurodegeneration}

Given the evidence for neurotrophic regulation of neuronal survival during development, it has been speculated that loss of retrogradely derived neurotrophic support might underlie or contribute to certain patterns of neurodegeneration in conditions such as Alzheimer's disease. Our findings suggest that a loss of target-derived neurotrophic factors seems unlikely on its own to be a major cause of neuronal cell death of mature basal forebrain cholinergic neurons, since declines by over $90 \%$ in the total hippocampal levels of mRNA for NGF and BDNF did not lead to a loss of afferent septal cholinergic neurons for over 
16 months in rats. This survival time constitutes over half of the normal lifetime of the animals studied, but we cannot rule out that loss of neurotrophic support over a longer time period in a longer-lived species may eventually lead to cell death. In addition, even though neurons deprived of target-derived neurotrophins did not die, these neurons did undergo substantial ncuronal atrophy in the form of ccll shrinkage and reduced staining for transmitter-synthesizing enzyme. A similar form of atrophy has been noted in Alzheimer's disease (Pearson et al., 1983; Allen et al., 1988), but whether neuronal atrophy in pathologic conditions is due to loss of target-derived neurotrophic factors is not clear. There appears to be no decline in neocortical or hippocampal concentrations of NGF or its mRNA in Alzheimer's disease (Goedert et al., 1986, 1989), although a decline in BDNF mRNA has been reported (Phillips et al., 1991). We have recently found that septal cholinergic neurons of aged rats show impaired retrograde labeling with ${ }^{125}$ I-NGF, and that nontransporting neurons are severely shrunken and atrophied. Expression of the high-affinity NGF receptor (p140 $\left.{ }^{\text {rk }}\right)$ is reduced in the septal region of these aged rats, suggesting that an intrinsic reduction in the capacity of these cells to derive receptor-mediated retrograde neurotrophic support may contribute to agerelated degenerative changes (J. D. Cooper, D. Lindholm, and M. V. Sofroniew, unpublished observations).

\section{Functions of target-derived neurotrophic factors in the adult CNS}

Numerous growth factors that might exert neurotrophic functions have been identified in the mature CNS, but the nature of those functions is not well understood. Studies on the developing PNS suggest that neurotrophic factors are produced in limiting amounts that regulate the survival of afferent neurons and collateral projections in proportion to target size (Thoenen and Barde, 1980; Barde, 1989). Our findings suggest that this hypothesis cannot be extrapolated without modification from the developing PNS to the adult CNS. Two well-characterized neurotrophic factors, NGF and BDNF, do not regulate the survival of septal cholinergic neurons in proportion to the number of target neurons in adult rats. These observations do not preclude the possibility that NGF may regulate the survival of septal cholinergic neurons during critical periods of development. We have found that withdrawal of NGF is lethal to developing but not mature septal cholinergic neurons in vitro (Svendsen et al., in press). Similar observations have been reported for dorsal root ganglion neurons (Eichler and Rich, 1989). If NGF is an absolute survival factor for septal cholinergic neurons in mature animals, then they appear to require so little that they are able to obtain enough to remain alive from even a few target neurons or glial elements, such that $10 \%$ of the target tissue and $10 \%$ of target neurotrophin mRNA levels can maintain essentially $100 \%$ of the afferent population of neurons. Although our findings suggest that the survival of mature CNS neurons is not acutely regulated in proportion to target-derived neurotrophic support, they also suggest that the production of transmitter-synthesizing enzyme and size of these neurons may be regulated in such a manner.

\section{References}

Abercrombie M (1946) Estimation of nuclear populations from microtome sections. Anat Rec 94:239-247.

Alderson RF, Alterman AL, Barde Y-A, Lindsay RM (1990) Brain- derived neurotrophic factor increases survival and differentiated functions of rat septal cholinergic neurons in culture. Neuron 5:297-306.

Allen SJ, Dawbarn D, Wilcock GK (1988) Morphometric immunochemical analysis of neurons in the nucleus basalis of Meynert in Alzheimer's disease. Brain Res 454:275-281.

Anderson KJ, Dam D, Lee S, Cotman CW (1988) Basic fibroblast growth factor prevents death of lesioned cholinergic neurons in vivo. Nature 332:360-361.

Ayer-LeLievre C, Olson L, Ebendal T, Seiger A, Persson H (1988) Expression of the $\beta$-nerve growth factor gene in hippocampal neurons. Science 240:1339-1341.

Bakhit C, Armanini M, Bennett GL, Wong WLT, Hansen SE, Taylor $R$ (1991) Increase in glia-derived nerve growth factor following destruction of hippocampal neurons. Brain Res 560:76-84.

Barde YA (1989) Trophic factors and neuronal survival. Neuron 2:1525-1534.

Campenot RB (1977) Local control of neurite development by nerve growth factor. Proc Natl Acad Sci USA 74:4516-4519.

Chandler CE, Parsons LM, Hosang M, Shooter E (1984) A monoclonal antibody modulates the interaction of nerve growth factor with PC12. J Biol Chem 259:6882-6889.

Cheng B, Mattson MP (1991) NGF and bFGF protect rat hippocampal and human cortical neurons against hypoglycemic damage by stabilizing calcium homeostasis. Neuron 7:1031-1041.

Chomczynski P, Sacchi N (1987) Single-step method of RNA isolation by acid guanidium-thiocyanate-phenol-chloroform extraction. Anal Biochem 162:156-159.

Cucllo AC, Sofronicw M (1984) The anatomy of the CNS cholinergic neurons. Trends Neurosci 7:74-78.

Dawbarn D, Allen SJ, Semenenko FM (1988) Coexistence of choline acetyltransferase and nerve growth factor receptors in the rat basal forebrain. Neurosci Lett 94:138-164.

Eckenstein F, Sofroniew MV (1983) Identification of central cholinergic neurons containing both choline acetyltransferase and acetylcholinesterase and of central neurons containing only acetylcholinesterase. J Neurosci 3:2286-2291.

Eckenstein F, Theonen H (1982) Production of specific antisera and monoclonal antibodies to choline acetyltransferase; characterization and use for identification of cholinergic neurons. EMBO J 1:363-368.

Eichler ME, Rich KM (1989) Death of sensory ganglion neurons after acute withdrawal of nerve growth factor in dissociated cell cultures. Brain Res 482:340-346.

Gage FH, Batchelor P, Chen KS, Chin D, Higgins GA, Koh S, Deputy S, Rosenberg MB, Fischer W, Bjorklund A (1989) NGF receptor reexpression and NGF-mediated cholinergic neuronal hypertrophy in the damaged adult neostriatum. Neuron 2:1177-1184.

Gasser UE, Weskamp G, Otten U, Dravid AR (1986) Time course of the elevation of nerve growth factor (NGF) contents in the hippocampus and septum following lesions of the septohippocampal pathway in rats. Brain Res 376:351-356.

Gnahn H, Hefti F, Heumann R, Schwab ME, Thoenen H (1983) NGFmediated increase of choline acetyltransferase (ChAT) in the neonatal rat forebrain: evidence for a physiological role of NGF in the brain. Dev Brain Res 9:45-52.

Goedert MA, Fine A, Dawbarn D, Wilcock GK, Chao M (1989) Nerve growth factor mRNA distribution in human brain: normal levels in basal forebrain in Alzheimer's disease. Mol Brain Res 5:1-7.

Greene LA (1977a) Quantitative in vitro studies on the nerve growth factor (NGF) requirement of neurons. I. Sympathetic neurons. Dev Biol 58:96-105.

Greene LA (1977b) Quantitative in vitro studies on the nerve growth factor (NGF) requirement of neurons. II. Sensory neurons. Dev Biol 58:106-113.

Hagg T, Quon D, Higaki J, Varon S (1992) Ciliary neurotrophic factor prevents neuronal degeneration and promotes low affinity NGF receptor expression in the adult rat CNS. Neuron 8:145-158.

Hedreen JC, Bacon SJ, Price DL (1984) A modified histochemical technique to visualise acetylcholinesterase-containing axons. J Histochem Cytochem 33:134-140.

Hefti F (1986) Nerve growth factor promotes survival of septal cholinergic neurons after fimbrial transections. J Neurosci 6:2155-2162.

Higgins GA, Koh S, Chen KS, Gage FH (1989) NGF induction of NGF receptor gene expression and cholinergic neuronal hypertrophy within the basal forebrain of the adult rat. Neuron 3:247-256.

Hohn A, Lcibrock J, Bailey K, Barde Y-A (1990) Identification and 
characterization of a novel member of the nerve growth factor/brainderived neurotrophic factor family. Nature 344:339-341.

Holtzman DM, Li Y, Parada LF, Kinsman S, Chen C-K, Valleta JS, Zhou J, Long JB, Mobley WC (1992) pl40 trk mRNA marks NGFresponsive forebrain neurons: evidence that $t r k$ gene expression is induced by NGF. Neuron 9:465-478.

Hyman C, Hofer M, Barde YA, Juhasz M, Yancopoulos GD, Squinto SP, Lindsay RM (1991) BDNF is a neurotrophic factor for dopaminergic neurons of the substantia nigra. Nature 350:230-232.

Isacson O, Sofroniew MV (1992) Neuronal loss or replacement in the injured adult cerebral neocortex induces extensive remodelling of intrinsic and afferent neural systems. Exp Neurol 117:151-175.

Johnson EM, Gorin PD, Pearson J (1980) Dorsal root ganglion neurons are destroyed by exposure in utero to maternal antibody to nerve growth factor. Science 210:916-918.

Johnson EM, Rich KM Jr, Yip HK (1986) The role of NGF in sensory neurons in vivo. Trends Neurosci 9:33-34.

Knüsel B, Michel PP, Schwaber JS, Hefti F (1990) Selective and nonselective stimulation of central cholinergic and dopaminergic development in vitro by nerve growth factor, basic fibroblast growth factor, epidermal growth factor, insulin, and the insulin-like growth factors I and II. J Neurosci 10:558-570.

Knüsel B, Winslow JW, Rosenthal A, Burton LE, Seid DP, Nikolics K, Hefti F (1991) Promotion of central cholinergic and dopaminergic neuron differentiation by brain-derived neurotrophic factor but not neurotrophin 3. Proc Natl Acad Sci USA 88:961-965.

Kordower JH, Burke-Watson M, Roback JD, Wainer BH (1992) Stability of septohippocampal neurons following excitotoxic lesions of the rat hippocampus. Exp Neurol 117:1-16.

Korsching S (1986) The role of nerve growth factor in the CNS. Trends Neurosci 9:570-573.

Kromer LF (1987) Nerve growth factor treatment after brain injury prevents neuronal death. Science 235:214-216.

Lams BE, Isacson O, Sofroniew MV (1988) Loss of transmitter-associated enzyme staining following axotomy does not indicate death of brainstem cholinergic neurons. Brain Res 475:401-406.

Lauterborn JC, Isackson PJ, Gall CM (1991) Nerve growth factor mRNA-containing cells are distributed within regions of cholinergic neurons in the rat basal forebrain. J Comp Neurol 306:439-446.

Leibrock J, Lottspeich F, Hohn A, Hofer M, Hengerer B, Masiakowski P, Thoenen H, Barde Y-A (1989) Molecular cloning and expression of brain derived ncurotrophic factor. Nature 341:149-152.

Levi-Montalcini R, Angeletti P (1968) Nerve growth factor. Physiol Rev 48:534-569.

Lindholm D, Heumann R, Meyer M, Thoenen H (1987) Interleukin-1 regulates synthesis of nerve growth factor in non-neuronal cells of rat sciatic nerve. Nature 330:658-659.

Lindholm D, Castren E, Kiefer R, Zafra F, Thoenen H (1992) Transforming growth factor-b1 in the rat brain: increase after injury and inhibition of astrocyte proliferation. J Cell Biol 117:395-400.

Lindsay RM (1979) Adult rat brain astrocytes support survival of both NGF-dependent and NGF-insensitive neurons. Nature 282:80-82.

Maisonpierre PC, Belluscio L, Squinto S, Ip NY, Furth ME, Lindsay RM, Yancopoulos GD (1990) Neurotrophin-3: a neurotrophic factor related to NGF and BDNF. Science 247:1446-1451.

Mobley WC, Rutkowski JL, Tennckoon GI, Buchanan K, Johnston MV (1985) Choline acetyltransferase activity in striatum of neonatal rats increased by nerve growth factor. Science 229:284-287.

O'Brien TS, Svendsen CN, Isacson O, Sofroniew MV (1990) Loss of True blue labelling from the medial septum following transection of the fimbria-fornix: evidence for the death of cholinergic and noncholinergic neurons. Brain Res 508:249-256.

Paxinos G, Watson C (1986) The rat brain in stereotaxic coordinates, 2d ed. Sydney: Academic.
Pearson RCA, Sofroniew MV, Cuello AC, Powell TPS, Eckenstein F, Esiri MM, Wilcock GK (1983) Persistence of cholinergic neurons in the basal nucleus in a brain with senile dementia of the Alzheimer's type demonstrated by immunohistochemical staining for choline acetyltransferase. Brain Res 289:375-379.

Phillips HS, Hains JM, Laramee GR, Rosenthal A, Winslow JW (1990) Widespread expression of BDNF but not NT3 by target areas of basal forebrain cholinergic neurons. Science 250:290-294.

Phillips HS, Hains JM, Armanini M, Laramee GR, Johnson SA, Winslow JW (1991) BDNF mRNA is decreased in the hippocampus of individuals with Alzheimer's disease. Neuron 7:695-702.

Seiler M, Schwab M (1984) Specific retrograde transport of nerve growth factor (NGF) from neocortex to nucleus basalis in the rat. Brain Res 300:33-39.

Sendtner M, Kreutzberg GW, Thoenen H (1990) Ciliary neurotrophic factor prevents the degeneration of motor neurons after axotomy. Nature 345:440-441.

Sofroniew MV, Isacson O (1988) Distribution of degeneration of cholinergic neurons in the septum following axotomy in different portions of the fimbria-fornix: a correlation between degree of cell loss and proximity of neuronal somata to the lesion. J Chem Neuroanat 1:327337.

Sofroniew MV, Isacson O, Bjorklund A (1986) Cortical grafts prevent atrophy of cholinergic basal nucleus neurons induced by excitotoxic cortical damage. Brain Res 378:409-415.

Sofroniew MV, Pearson RCA, Powell TPS (1987) The cholinergic nuclei of the basal forebrain of the rat: normal structure, development and experimentally induced degeneration. Brain Res 411:310-331.

Sofroniew MV, Galletly NP, Isacson O, Svendsen CN (1990) Survival of adult basal forebrain cholinergic neurons after loss of target neurons. Science 247:338-342.

Spranger M, Lindholm D, Bandtlow C, Heumann R, Gnahn H, NaherNoe M, Thoenen H (1990) Regulation of nerve growth factor(NGF) synthesis in the rat central nervous system: comparison between the effects of interleukin-1 and various growth factors in astrocyte cultures and in vivo. Eur J Neurosci 2:69-76.

Svendsen CN, Kew JNC, Staley K, Sofroniew MV (in press) Death of developing septal cholinergic neurons following NGF withdrawal in vitro: protection by protein synthesis inhibition. J Neurosci, in press.

Taniuchi M, Schweitzer JB, Johnson EMJ (1986) Nerve growth factor receptor molcculcs in rat brain. Proc Natl Acad Sci USA 83:19501954.

Thoenen H, Barde YA (1980) Physiology of nerve growth factor. Physiol Rev 60:1284-1335.

Tuszynski MH, Armstrong DM, Gage FH (1990) Basal forebrain cell loss following fimbria/fornix transection. Brain Res 508:241-248.

Wetmore C, Ernfors P, Persson H, Olson L (1990) Localization of brain-derived neurotrophic factor mRNA to neurons in the brain by in situ hybridization. Exp Neurol 109:141-152.

Williams LR, Varon S, Peterson GM, Wictorin K, Fischer W, Bjorklund A, Gage FH (1986) Continuous infusion of nerve growth factor prevents basal forebrain neuronal death after fimbria fornix transection. Proc Natl Acad Sci USA 83:9231-9235.

Wood SJ, Pritchard J, Sofroniew MV (1990) Re-expression of nerve growth factor receptor after axonal injury rccapitulates a developmental event in motor neurons: differential regulation when regeneration is allowed or prevented. Eur $\mathrm{J}$ Neurosci 2:650-658.

Zafra F, Hengerer B, Leibrock J, Thoenen H, Lindholm D (1990) Activity dependent regulation of BDNF and NGF mRNAs in the rat hippocampus is mediated by non-NMDA glutamate receptors. EMBO J 9:3545-3550. 